\title{
Index for Volume 90
}

AUTHOR AND SUBJECT INDEX. Pages indicating errata are in italic. "S" indicates June abstract supplement. Publication number P-2000-1020-01O.

Abbas, H. K., S1, S9

Abdul-Kader, A. M., S65

Abdurahman, M. D., 537

Abney, T. S., S15

Abou-Ghanem, N., S88

Abou-Zeid, N. M., 1182

Abstracts, author index and division meeting presentations, S135

Abu-El Samen, F., S1

Acidovorax avenae

-on cucurbits, seed transmission, S126

-molecular characterization, 340

-strain diversity from cucurbits, DNA fingerprinting and fatty acid analysis, 191

-on watermelon, field movement in Texas, S38

Aconitum latent virus, on Aconitum napellus

- doubly infected with Cucumber mosaic virus, cover photo, April

-molecular characterization, 340

Acosta, J., S24

Acosta, L. I., S1

Adachi, Y., 1209, S47

Adair, R. C., S30

Adams, P. D., S2

Adaskaveg, J. E., 171, S2, S119, S121

Adee, E. A., 875

Adkins, S., S2, S22

Aegerter, B. J., S2

Agrobacterium spp.

-A. tumefaciens: detection in soil, S121; genomic analysis, S93; hydrogen peroxide detoxified by catalase, $\mathrm{S} 86$

-A. vitis, on grape, biocontrol enhanced by trifolitoxin, S35

Ahn, I. P., S42

Ahoonmanesh, A., 629

Ajwa, H. A., S102

Akimitsu, K., 762

Akingbe, O. O., 812

Akridge, J. R., S32, S65

Alabouvette, C., 1279

Al-Adawi, A. O., 928

Alarcon-Chaidez, F., S81

Alavi, S., 699

Albana, J. L., S11

Albiach-Martí, M. R., 134, S2, S30, S69

Albino, M. M. C., S23

Alcantara, S., S123

Aldwinckle, H. S., 72, S56, S64, S65

Alessandro, R., S74

Alexander, H. M., 1181

Alexander, S. A., S132

Alfalfa

-bacterial root rot, regression analyses and variable disease intensity, yield, 657

$-S$. enterica mutants, sprout growth reduction, S13

Ali, G. S., S117

Ali, S., S2

Alkylresorcinol, disease resistance source in cereal grain, S65

Allan, M. A., S2

Allen, T. W., Jr., 88

Allen, C., S37

Allen, E., S111

Allen, R., S82

Alliot, B., 505

Alminaite, A., S39

Almond

- cold storage canker, etiology in California, S49

-Colletotrichum spp., molecular analyses, 608

-Phytophthora canker, chemical management, S10

Al-Subhi, A. M., 928
Alternaria spp., on citrus, host specificity, population structure, 407

-A. alternata: on apple, detection with PCR method, 973; mycelial growth, monoterpene effect, S30; on persimmon, gibberellin treatment effect, 1256; on strawberry, infectioninhibiting factor, 595; on tangerine, $A K T$ homologs, 762; on tobacco, resistance and riboflavin, 801

Alvarez, A. M., S3, S47, S71

Alvarez, E., S2, S3

Alzate-Marin, A. L., 758

Ambruzs, B. D., S117

American Phytopathological Society

—abstracts, author index, S135

-annual and division meeting presentations, author index, S135

—annual meeting abstracts, $\mathrm{S} 1$

-annual report, 15

- excellence in extension award, 27

-fellows, 22

-Lee M. Hutchins award, 28

-Novartis award, 29

-officers, representatives, and committees, 13

-presidential address, 17

-Ruth Allen award, 30

Ames, K. A., S3

Ammermann, E., S3

Anandalakshmni, R., S127

Andersen, P. C., S54

Anderson, J. A., 699, 812

Anderson, M. G., S131

Anderson, N. A., S73

Anderson, O., S57

Anderson, R. L., S97

Anderson, T. E., S134

Andrews, D. L., S28

Andries, C., S86

Angell, S., S112

Anziani, C., 730

Aparicio, F., 1330

Apel-Birkhold, P. C., 699, 812, S4

Aphanomyces spp.

-A. cochlioides: spore production, variability, S9; on sugar beet, genetic diversity, letter to editor, 565

-A. euteiches, detection, PCR-based assay, 1137

Aphis gossypii, vector for Cucumber mosaic virus, satellite RNA effect, 1068

Apple

-Alternaria blotch, detection with PCR method, 973

-arthropod and pathogen management, leaf litter and urea effect, S29

-Botrytis cinerea, calcium inhibitory to, 769

- fire blight: benzothiadiazole derivative effect on, S49; environmental factors, 1285; integrated control, S64; resistance inheritance, S56

- postharvest decay, biocontrol and heat treatment combination, S46

-replant disease, wheat cultivation effect, 114

-replant soil, microbial management, S102

- resistance and DNA technologies, S109

-scab: biocontrol, 31; races 6 and 7 of Venturia inaequalis, host-pathogen genetics, 236; resistance and endochitinase from Trichoderma, 72

- shoot blight, prohexadione calcium effect, S35

- sooty blotch, temperature and relative humidity effect, 362

Apple chlorotic leaf spot virus

-on Nicotiana occidentalis, Grapevine berry inner necrosis virus resistance, 311

-on transgenic Nicotiana occidentalis, cover photo, March
Apple mosaic virus, detection with molecular hybridization and polymerase chain reaction, 1330

Arabidopsis sp.: hypersensitivity and defense, cell death pathway, S40; powdery mildew, systemic acquired resistance, $\mathrm{S} 63$

-A. thaliana: diseases of, riboflavin effect, 801; Fusarium wilt, host-pathogen interaction model, S54; resistance gene RPS2, interacting proteins, S33; Turnip yellow mosaic and Tobacco mosaic viruses, seed transmission, 1233

Aragão, F. J. L., S23

Archer, C., S85

Ardales, E., S108

Arlat, M., S93

Armillaria spp.: matings, assessment techniques, S42; in Ozark forests, harvest disturbance, S10

- A. tabescens, rhizomorph generation, moisture and oxygen effect, $\mathrm{S} 11$

array, $\mathrm{S} 8$

Arnold, J., S87

Arseniuk, E., S6, S17

Arthrobotrys haptotyla, nematode parasite, use in biocontrol, 498

Artiguenave, F., S93

Arul, J., S51

Aryantha, I. P., 775

Ash, anthracnose, variation in susceptibility, S38

Ashfield, T., S110

Aspergillus spp.: aflatoxin biosynthesis, S96; section Flavi, aflatoxins in shrubs and tress, S8; US and African strain comparison, aflatoxin, S11

-A. flavus: aflatoxin biosynthesis, gene expression, S56; aflatoxin detection, kojic acid, S80; on corn, ear rot and aflatoxin production, resistance, 292; interaction with Fusarium verticillioides and insects, in corn, in Africa, 276; pectinase activity, isolates in southern USA, S52

Assemat, P., S57

Assis Filho, F. M., S125

Astua-Monge, G., S110

Atabekov, J. G., S111

Atia, M., S22

Attias, M., 1032

Avantaggiato, G., S40

Avila-Adame, C., S3

Avocado, Colletotrichum gloeosporioides, unripe fruit infection, 553

Aycock, R., 564

Ayllón, M. A., S3, S30, S67

Aylor, D. E., 78, S50

Baayen, R. P., 867, 891

Babadoost, M., S3, S131

Bacillus spp.

$-B$. cereus, on alfalfa, regression analyses, variable disease intensity, 657

-B. mojavensis, biocontrol agent, host range, S4

-B. subtilis, biofungicide from, mechanism, S87

Bacon, C. W., S4, S27

Bacteria

-antibiotic resistance, mechanisms, S100

-pathogen genomics, S92

—plant association, genomic analysis, S93

-plant recognition, oxygen uptake response, S4

—population composition, biofilm effect, S101

- soil, functional diversity, S133

Bactericides, tomato bacterial canker, disease and yield effects, 38

Badel, J. L., S4, S24

Badgley, A. K., S66 
Bai, G., S4

Bai, J., S4

Baider, A., 1105

Bailey, B. A., 691, 699, 812, S4

Bailey, C., S132

Bajt, S., S37

Baker, C. J., S4, S65

Balaban, M. O., S113

Balardin, C. R., S4

Balardin, R. S., S4

Balasubramanian, S., S5, S88

Baldridge, G. D., S35

Baldwin, M., S132

Ballester-Olmos, J. F., 134

Banana

-Panama disease, race 4 resistance, 1173

-Septoria leaf spot, identification, 884

Banana streak virus, genetic diversity, Australian isolates, 921, 1295

Bananej, K., 629

Banks, D., S13

Banksia spinulosa, Phytophthora cinnamomi on, suppression by composted manure, 775

Bannwart, D. L., S30

Barak, J. D., S5

Barash, I., S22

Barbe, V., S93

Barber, K. L., S3

Barbierri, L., S30

Bardinelli, T. R., S5, S53

Barker, I., 448, S43

Barley

-basal kernel blight, control with Pseudomonas syringae and Pantoea spp., 368

-Fusarium head blight, quantitative trait loci, mapping and resistance, 1079

-leaf blotch, genetic structure of field populations, 901

—leaf rust, resistance genetics, 1131

- loose smut, carboxin resistance, 179

- plant virus survey, in Alaska, S66

- polymerase, RNA-directed, characterization, S36

- powdery mildew, seed treatment with Chaetomium, S64

—scald, histopathology, resistance, 94

Barley yellow dwarf virus

-serotypes, analysis and modeling, 860

- survey in Virginia, S133

-translation event and long-distance control, S111

—in wheat, yield effects, 1043

Barnes, I., S5

Barnes, J. S., S5, S53

Barnett, J. P., S81

Barrault, G., 915

Barros, T. S. L., S5

Barry, J., S111

Bartnicki-Garcia, S., S121

Barton, W. R., S5, S28

Bartz, J. A., S7

Barzuna, L., 615

Basaran, P., S11

Basil, Fusarium wilt, airborne conidia, 1322

Basim, E., S5, S6

Basim, H., S5, S6

Basinger, E., S87

Basnayake, M. D. V. R., S6, S131

Batten, J. S., S6

Batut, J., S92

Batzer, J. C., S27

Bauer, D. W., S65

Bauer, W. D., 327

Baulcombe, D. C., S112

Baum, T. J., S82

Bean (see also Phaseolus vulgaris)

-root rot, bacterial seed treatment, S22

- snap, ozone effect in New York, S133

—white mold, plant arrangement effect, S61
Bean common mosaic virus

- bean common mosaic necrotic virus comparison, molecular analysis, S24

-resistance genetics, S110

Bean dwarf mosaic virus, hypersensitivity and mapping, S87

Bean golden mosaic virus

- golden mosaic disease difference, in Puerto

Rico, S122

-resistance with mutant rep gene, S23

Bean golden yellow mosaic virus, pseudorecombination with other viruses, germ plasm screening, 1224

Bean pod mottle virus

-isolate diversity, cross-protection, S31

- on soybean, in South Dakota, S45

Bean, T. G., S6

Bean yellow mosaic virus, Clover yellow vein virus cross-protection, S68

Becherer, H. E., S10

Beck, J. J., S60

Becker, J. O., 401, S8, S117, S119, S120

Becker, R., S5, S53

Becton, C. M., S68

Bedford, I. D., S9

Been, T. H., 647

Beer, S. V., 801

Beet chlorosis virus, on beet, variability, 460

Beet curly top virus, capsid protein role, virus movement and insect transmission, S74

Beet mild yellowing virus and Beet western yellows virus, on sugar beet, variability, 460

Beet yellows virus, cell-to-cell movement, S91

Bekal, S., S117

Bell, J., 38

Bell, M. L., S127

Bemisia tabaci, Watermelon chlorotic stunt virus vector, Sudan and Iran, 629

Bénaouf, G., 236

Ben-Arie, R., 1256

Bender, C. L., S23, S41, S59, S63, S81, S88

Bender, D. A., S70

Benhamou, N., 45, 932

Bennett, R. S., S6

Beno-Moualem, D., 553

Benson, D. M., S36, S126

Bent, A. F., s33, S40, S110

Bentgrass, dollar spot, nitrogen, mowing, and fungicides, S19

Bentley, E. M., S117

Ben-Yehuda, P., 601

Berestecky, J., S3

Berg, M., S6, S63

Berger, R. D., S128

Berges, R., 1145

Bergstrom, G. C., S6

Berka, R., S57

Bermuda grass etched-line virus, Iranian isolate, cloning and sequencing, S38

Bermudagrass, dematiaceous fungi, waste application sites, Mississippi, S61

Bernal, J. J., 1098

Bernhard, F., S6

Bernier, J., 31

Bernier, L., S21

Berrie, A. M., 1367

Berry, J. A., S112

Berthier-Schaad, Y., 951

Bertrand, P. F., S9

Berube, J. A., S73

Beyer, D. M., S6, S38, S131

Beyl, C. A., S35, S58

Bhaskara Reddy, M. V., S64

Bhat, R. G., S7

Bhatnagar, D., S107

Bijman, V. P., S54, S120

Billau, A., S93

Biological control

-AQ10 biofungicide, case study, S101
-Arthrobotrys and Hirsutella spp. for nematodes, 498

-Dendryphion penicillatum and Pleospora papaveracea, on poppy, mycoherbicides, 691

-Fusarium for Pleospora papaveracea, on poppy, 812

- grapefruit postharvest decay, antagonist dynamics, 1217

- Pantoea agglomerans and Trichoderma hamatum for radish bacterial leaf spot, 327

-in parthenium, management in India, S61

-Penicillium oxalicum for Fusarium oxysporum on tomato, 260

-phyllosphere, Serenade, S101

- postharvest disease on fruits, mechanism, 1196

-potting mixes for Phytophthora cinnamomi, 775

- Pseudomonas syringae and Pantoea agglomerans for barley basal kernel blight, 368

- Pythium on cucumber, suppressive microflora, 125

-Pythium ultimum on roots, disease progression using rhizobox, 1049

- screening methods, comparison of, S50

- Serratia plymuthica for Pythium on cucumber, 45

-Stenotrophomonas maltophilia for Bipolaris sorokiniana, chitinase role, 384

- tomato and pepper diseases, chemical control comparison, S85

- Trichoderma virens for Rhizoctonia solani, on cotton, 248

Biotechnology

—bacteria, genes, genomes, S109

-food safety, S104

- GM foods controversy, S104

-health and economic development, future in Third World, S95

-industry perspective, S94

-pathogen detection and disease diagnosis, S109

—plant virus research, S123

— transgenes from biocontrol microbes, S109

-transgenic trees, S105

-world wheat trade, S104

Bipolaris sorokiniana, on tall fescue, control by Stenotrophomonas maltophilia, chitinase role, 384

Bird, J., S122, S122

Birkes, D. S., S27

Bishop, D. G., S58

Bishop-Hurley, S. L., S7

Bissonnett, S. M., S112

Blacharski, R. W., S7

Blachere, F. M., S7

Blake, D. R., S102

Blakeslee, G., S104

Blanchette, R. A., S7, S34, S40, S73

Blattner, F. R., S92

Blechl, A., S57

Bliss, W., 615

Blodgett, J. T., S7

Blok, W. J., 253

Blom, T. J., S30

Blueberry

-Monilinia vaccinii-corymbosi, phenology, 390

- scorch disease, virus transmission, cultivars, and yield, 474

- surfactant injury, diagnosis in North Carolina, $\mathrm{S} 15$

Blueberry red ringspot virus, genome organization and sequence analysis, S27

Blueberry scorch virus

-on highbush blueberry, transmission, cultivars, and yield, 474

- oak-leaf line pattern on blueberry, cover photo, May

Bo, L., S8

Boehm, E. W., S8 
Boehm, M. J., S33, S42, S69

Boge, W. L., 1137

Boisne-Noc, R., s18

Bolar, J. P., 72

Bollen, G. J., 253

Bonacci, B. B., S33

Bonants, P. J. M., 867, 891

Bonde, M. R., 951, S25, S131

Bonello, P., S8

Bonierbale, M., S68

Boonham, N., 448, S43

Borejsza-Wysocka, E. E., S56, S65

Borneman, J., S8

Bosmans, R. V., S106

Bosque-Pérez, N. A., 276

Bost, S. C., S84

Bostanian, N. J., S5

Bostick, J. P., S8

Bostock, R. M., S49

Botha, W. J., S69

Bothe, G., S92

Botryosphaeria dothidea

-iprodione resistance, S49

—on pistachio, latent infection, S56

Botrytis spp.

-B. cinerea: on apple, calcium inhibitory effect, 769; on carrot, resistance induced in storage, 981; dicarboximide resistance, 1246; fungicide resistance, genetic analysis, 851 ; on strawberry flowers, modeling infection, 1367

-B. fabae, on faba bean, biocontrol in Egypt, 1182

Boucher, C., S9

Boureau, T., S101

Bourgeois, G., 1120

Bowden, R. L., S40

Bowen, K. L., S8, S11

Bowers, J. H., S8

Bowman, N. D., S112

Boyd, M. L., S8

Boydston, C. M., S19

Boyette, C. D., S1, S9, S98

Brantner, J. R., S9

Brassica napus, Leptosphaeria maculans, pathosystem, resistance sources and durability, field evaluation, 961

Brassica yellowing virus, on rape, variability, 460

Braun-Kiewnick, A., 368

Bremia lactucae, on lettuce

— spore release, factors, 67

—survival factors, 827

Brener, S., 834

Brenneman, T. B., S9, S125

Briddon, R. W., S9

Brigneti, G., S112

Brill, W., S113

Bristow, P. R., 474, S9, S117

Britton, K. O., S39

Brlansky, R. H., S9, S36

Broad bean wilt virus, on pepper, 1390; cover photo, December

Brodeur, J., 932

Brome mosaic virus, plant guttation effect, S19

Brooks, W. S., 1131

Brottier, P., S93

Brown, A., S73

Brown, C. R., S118

Brown, E. A., S112

Brown, J. K., 546, S10, S37, S122

Brown, J. K. M., 320

Brown, M., S60

Brown, R. L., S14, S27

Brown, S. E., S93

Brown, S. K., S56

Brown, S. L., S83, S99

Brown, W., S30

Brown, W. Y., S105

Browne, G. T., S10, S83

Browning, J. A., 676
Bruckart, W. L., S10, S87

Bruhn, J. N., S10, S11

Brun, H., 961

Bruton, B. D., S18, S24, S63, S101, S123

Bryan, T. G., S110

Büche, C., S67

Buchenauer, H., S22, S55

Buckler, E. S., S95

Bukhalid, R. A., S47, S66

Bull, C. T., S15, S72, S102

Burch, K. B, S8, S11

Burdon, J. J., 901

Burkholderia spp.

-B. cepacia, on onion, watersoaking and porin protein gene, S51

- B. vietnamiensis, antibiotic production, genetics, S34

Burland, V., S92

Burnett, P. A., 94

Burnside, J., S6, S131

Burpee, L. L., S96

Burr, H. N., S85

Burr, J. A., S85

Burr, T. J., S11

Bush, J., S20, S34, S70

Bushnell, W. R., S35

Bushong, P. M., S125

Busto, J., S92

Butrón, A., S32

Butterfield, E. J., S28, S74

Butternut, canker, metabolite toxicity of Sirococcus sp., S74

Butterworth, S. C., S11

Buyer, J. S., S65, S133

Cabrera, O., 977

Caciagli, P., 629

Cahn, M. D., S68, S121

Cambra, M., 1337

Campbell, C. L., S21

Campbell, L., S51

Cançado, L. J., S23

Cancro, R., S11

Candresse, T., 522

Cantaloupe (see also Melon, Muskmelon): bacterial blight, genetic diversity, in France, 636

Capsicum spp.

-C. annuum: insects and bacteria, S124; Phytophthora blight, inoculum dispersal, dynamics, 148; RNA, Broad bean wilt virus effect, 1390; root-knot, biocontrol, S53; Xanthomonas campestris, races and necrosis, S74

-C. chinense, Tobacco etch virus, field spread in Jamaica, S50

Cardin, L., 522

Cardwell, K. F., 276, S11

Carey, W. A., S71

Carica papaya, viruses of, molecular study, S56

Carisse, O., 31, 1120

Carle, S. A., S11

Carlier, J., 884

Carling, D. E., S129

Carlisle, D. J., S12, S19

Carnation ringspot virus, capsid protein, mutation, S32

Carras, M. M., 1126, S77

Carrera, L. M., S12

Carrington, M. E., S124

Carris, L. M., 376

Carroll, B. R., S114

Carroll, J. E., S12

Carroll, R. B., S131

Carrot

- Botrytis cinerea, resistance induced in storage, 981

—root rot and seedling diseases, Georgia, S129

Carta, L., S53
Carter, Jr., S., S52

Carter, L., S51

Carter, S. A., S12

Cartwright, R. D., 1396, S1, S99

Cary, J., S107

Casper, H., S129

Cassava, bacterial blight, genetic diversity of bacteria in Colombia, 683

Catranis, C. M., S12, S46

Cattolico, L., S93

Cauliflower, Verticillium wilt

—broccoli-mediated reduction, mechanism, 305

—irrigation effect, 995

Cauliflower mosaic virus

-hypersensitivity and agroinfiltration, in tobacco, S41

-translation strategy, bakers' yeast, S111

Cavaletto, J. R., S29

Celebi-Toprak, F., S12

Celmer, A. F., S4

Cenococcum geophilum, in serpentine soils, diversity, S71

Cephalosporium maydis, on corn, diversity in Egypt, S68

Ceratocystis spp.

-C. fagacearum, on oak, Gliocladium roseum for control, S55

$-C$. fimbriata, on almond, topical treatments, S29

Cercospora spp.

-C. kikuchii, polyketide synthase, S79

-C. zeae-maydis: on corn, African and US populations, genetic relatedness, 486; on corn, resistance and trait loci, 1018; on corn, rRNA genes, S134

Cereal, rusts, variation and resistance breeding, S94

Cerkauskas, R. F., S12

Cha, J.-S., S13

Cha, S. H., S39

Chagas, J. M., 758

Chakraborty, S., S83

Chambers, J., S94

Champaco, E. R., S31

Champoiseau, P., S18

Chandler, C. K., S46

Chang, C. J., S13

Chang, P. K., S107

Chang, S., S13

Chapman, S. R., S38

Chappelka, A. H., S22

Chappell, C., S65

Chardonnet, C. O., 769

Charkowski, A., S13

Charlton, N. D., S13, S81

Charter, E. A., S26

Chase, T. E., S13

Chastagner, G. A, S117

Chayote mosaic virus, on Cucurbitaceae, new tymovirus, 1098

Chellemi, D. O., 1079, S102

Chen, J., S13

Chen, M. H., 94

Chen, S. Y., S14

Chen, W., 875, S37, S52

Chen, X. M., S14

Chen, X., S54

Chen, Y. F., S13

Chen, Z.-Y., S14

Chenault, K. D., S14

Chenopodium quinoa, downy mildew, in Peru, S17

Cherry

—early brown rot, Monilinia-specific DNA primers, 171

- little cherry disease viral agent association, S67

Cherry necrotic mottle virus, nucleotide sequence, S67 
Chestnut, blight, vegetative compatibility types, hypovirulence and biocontrol, in France, 730

Cheung, K. W., S14

Chèvre, A. M., 961

Chiang, C.-H., S14

Chin, K. M., S100

Chino del tomate virus, begomovirus relations, component variance and symptoms, 546

Chitwood, D. J., S53, S56

Chiu, S. W., S14

Chiyembekeza, A. J., 214

Cho, J. H., S28

Cho, J. M., S39, S42

Cho, M. J., S42

Choi, I.-R., S25

Choi, K. C., 1390

Choi, S., S4

Choi, W., S14, S40

Choi, Y. M., S49

Choisne, N., S93

Chou, C. C., S14, S15

Choueiri, E., S68

Christ, B. J., S62

Chuma, I., 1060

Chung, Y. R., S42

Cicer arietinum

-Ascochyta blight, management by resistance and fungicides, 834

—Fusarium wilt, epidemics and yield loss, 1269

- potyvirus on, molecular characterization, in Bolivia, S45

Cigelnik, E., 891

Cilliers, A. J., 1026

Cintas, N. A., S15

Circulifer tenellus, Spiroplasma citri vector, surface protein P89 in adhesion to, 716

Cisar, G., 1043

Citovsky, V., S112

Citrus

- Alternaria alternata on, tangerine pathotype, AKT homologs, 762

—brown spot, host specificity, in Florida, 407

- budwood certification program, Texas, S40

- canker, meteorological effect, S29

- foliar diseases, control with Flint in Florida, S129

- greasy spot and Phytophthora diseases, aerial digital imagery, S73

-Messenger effect on disease control and fruit production, S64

- postharvest decay, resistance induced by Candida oleophila, S20

— scab and melanose, fungicides for, S125

Citrus grandis, Asiatic citrus canker, cultivar interactions, 1383

Citrus tatterleaf virus, tissue alteration by, $\mathrm{S} 80$

Citrus tristeza virus

- aphid and graft transmission, California, S72

-aphid transmission, RNA population of isolates, 134

-coat protein genes: sub-genomic promoters, S30; virion formation, S69

- detectable with co-infection, S61

- detection, antibody fusion proteins and ELISA, 1337

—diversity in California, S118

- genetics, S91

-host range, mapping, S2

-isolate characterization, Texas, S35

- mixed infections and recombination, S67

- molecular markers, S92

-origins and dissemination, S91

-subgenomic RNAs, mapping, S3

- subisolate separation using aphid, S9

-on sweet orange, histology, S36

Citrus yellow mosaic virus, molecular characterization, S37

Civerolo, E. L., S16, S17

Cladosporium caryigenum, kresoxim-methyl sensitivity, S11

Clark, A., S31

Clark, C. A., S72

Clarke, B. B., S19, S79

Claroz, J. L., S3

Clavibacter michiganensis

— genomic analysis, S93

-on pepper, PCR analysis, S5

—on tomato, bactericides, 38

Claviceps spp., identification using rDNA intronbased diagnostic, S59

-C. africana: diversity, analysis, S77; diversity, RAM and AFLP analyses, 1126

-C. purpurea, ergopeptines and peptide synthetase genes, S96

Clement, D. L., S106

Clements, M. J., 1018, S15

Cleveland, T. E., S14, S27, S32, S107

Cline, W. O., S15

Clover, ozone effect, in New York, S50

Coates, D., S43

Cochliobolus heterostrophus, genomics, S109

Cochran, A. J., S15

Coelho, L., 1079

Coetzee, M. P. A., S5

Cohen, J., 340

Cohen, L., S20

Cohen, S. D., S15

Cohen, Y., 1105

Colbert, S. F., S15

Cole, A. B., S16, S41, S111

Colgrove, A. L., S16

Colgrove, K. B., S16

Colletotrichum spp.: on almond, molecular analyses, 608; genetic diversity and phylogenetics, polymorphism, S83; glutamine synthetase gene, characterization, S8; on strawberry, etiology and population genetics, S79; on strawberry, natural fungicide for, $\mathrm{S} 83$

-C. acutatum: on highbush blueberry, inoculum production and infection time, $\mathrm{S} 9$; host range in Japan, S68

-C. dematium, on mulberry, phytotoxins, 285

-C. gloeosporioides: on avocado, infection in unripe fruit, 553; on grapefruit and orange, postharvest, California, S119; RLGS profiles, nit 1 mutants, S77; on strawberry, other hosts, S86

-C. graminicola, pathogenicity mutants, S77

-C. lindemuthianum, on bean, resistance gene and molecular markers, 758

Collins, D. P., S101

Collins, J., S60

Collmer, A., S4, S24, S59, S63, S64, S66, S108

Collopy, P. D., S16

Colocasia esculenta

— pocket rot, etiology, S78

- taro paddy disease, pathology, S78

Colvin, J., 85

Conci, L. R., S40

Conn, K. L., S16, S73

Connor, J., S20, S34

Convolvulus arvensis, bacterial blight, in Idaho, S54

Conway, W. S., 769, S46, S87

Cook, D. L., S55, S84

Cook, D. R., S79

Cook, R. J., S63, S95, S103

Cooke, L. R., S12, S19

Cooperband, L. R., S79

Copes, W. E., 843

Coplin, D. L., 327

Corn (see also Maize)

-aflatoxin: herbicide treatment effect, S17; inbred resistance, $\mathrm{S} 85$

-aflatoxins and fumonisins, in Mississippi, S1

-Aspergillus ear rot, aflatoxin, resistance inheritance, 292

-beauvericin occurrence, in Croatia, S40 —cropping sequence effect, S14

-Fusarium ear rot, inoculation methods, S15

- gray leaf spot: African and US populations of Cercospora compared, 486; epidemiology and factors, S12; phylogenetics, S75; resistance and quantitative trait loci, 1018

-High Plains Disease, in Washington, S117

- stalk rot, Bt hybrid role in management, S27

- Stewart's disease, flea beetle populations, S21

- stunt spiroplasma, detection, PCR, S5

-sweet, Stewart's wilt: ratings and yield

relation, S25; and systemic infection, S53

Correa-Victoria, F. J., S94

Correll, J. C., 1396, S8, S16, S37, S44, S64

Corsini, D. L., S118

Cortesi, P., 730, 967

Costanzo, S., S62

Cotton

-aflatoxin, chemistry and seed treatment, S88

-bacterial blight, hypersensitivity and resistance genes, S59

—begomoviruses, New and Old World sources, S10

-leaf curl: disease induction, S9; epidemiology in Sudan, S37

-Phomopsis boll dangle, epidemic, S58

-reniform nematode: management with aldicarb and crop rotation, S18; in Tennessee, S55

- Rhizoctonia solani, Trichoderma virens seed treatment, terpenoid synthesis, 248

-root-knot nematode, remote sensing, nematicide application maps, S83

Cotty, P. J., S8, S11, S43, S52, S107

Couch, B. C., 514

Coutinho, T. A., S5, S16, S18, S67, S80

Cover photo

-Aconitum latent virus, on Aconitum napellus, Cucumber mosaic virus double infection, April

-Apple chlorotic leaf spot virus, on Nicotiana occidentalis, March

-Blueberry scorch virus, oak-leaf line pattern, May

-Broad bean wilt virus, on hot peppers, December

-Magnaporthe grisea, on rice leaves, October

-Penicillium digitatum and Verticillium lecanii, interaction, September

- Phoma macdonaldii, on sunflower, August

- Pleospora papaveracea on Papaver somniferum, July

- Pythium ultimum in cucumber, seed treatment effect, January

- sugarcane, yellow leaf syndrome, symptoms, February

-Venturia nashicola, on Japanese pear, cover photo, November

-Watermelon chlorotic stunt virus, June

Cowpea, protoplasts, polymerase isolation, S2

Cowpea chlorotic mottle virus, symptom determinant, mapping, S125

Cox, K. D., S17, S125

Cramer, C., S51

Cranberry

- fruit-rotting fungi, in Michigan, S57

—stem gall, identification, S80

Crawford, L. M., S104

Crawford, W. E., S126

Creager, R. A., S60

Creswell, T., S113

Crinivirus sp., detection and differentiation, $\mathrm{S} 92$

Cronartium spp.

-C. quercuum: on shortleaf pine, anatomy, S81; on slash pine, resistance components, 1005

-C. ribicola: on Pinus strobus, genetic diversity in population structure, 1073; on white pine, resistance and histology, S40

Crosby, D. G., S53, S71

Crowe, F., S118

Cross, R., 775 
Cryphonectria parasitica

-Activator-like transposon, S24

—on chestnut, past and prognosis, S97

- vegetative compatibility, hypovirulence and biocontrol, France, 730

Csinos, A. S., 139, S125

Cubeta, M. A., S82

Cucumber

-Colletotrichum and Didymella on, cultivar response, $\mathrm{S} 80$

- leaf spot, resistance in North Carolina, S21

- powdery mildew, control, S12

- pseudomonad and benzothiadiazole effect, S22

-Pythium ultimum, resistance mediated by bacteria, 45

—root and crown rot, Pythium aphanidermatum, 125

Cucumber green mosaic virus, resistance induced by Trichoderma spp., S47

Cucumber mosaic virus

- on Aconitum napellus, mixed infection with Aconitum latent virus, 340

—aphid transmission, satellite RNA effect, 1068

- detection, mouse monclonal antibodies, 615

-mutation and aphid transmission, S55

-on potato, temperature sensitivity, S12

—powdery mildew, Milsana Bioprotectant, S81

-root, crown, and foot rot, mefenoxam insensitivity, 396

-satellite RNA, virulence in populations, evolution, 480

-Zucchini yellow mosaic virus, amino acid change, 467

Cucurbit, yellow vine, Serratia marcescens strains, S63

Cucurbit leaf crumple virus, characterization in California, S35

Cucurbit leaf curl virus, in Arizona, Texas, and Mexico, new, S10

Cui, K. R., S17

Culbreath, A. K., 139, S83, S99, S114, S125, S128

Cultural diversity programs

-industry focus, S115

-recruitment and retention of minorities, S115

—urban forestry experience, $\mathrm{S} 115$

Culver, J. N., S112

Cumming, J. R., S44, S71

Cunfer, B. M., S3, S6

Curry, K. J., S129

Curtis, I. S., 1390

Cvjetkovic, B., S40

Cylindrocladium parasiticum

-microsclerotia, germination on clover roots, S63

- on peanut, seed transmission, S132

Cymbidium mosaic virus

- coat protein, orchid transformation, S82

-on orchid, molecular beacon approach, 269 Odontoglossum ringspot virus on orchid, molecular beacon approach, 269 Fusarium verticillioides Aspergillus flavus and insect interaction, on corn, Africa, 276 Aspergillus flavus interaction with Fusarium verticillioides and insects, in corn, in Africa, 276

Daboussi, M.-J., 1279

Dafalla, G. A., 629

da Graca, J. V., S35, S40

Dai, Q., S17

Dally, E. L., S5, S18

Dalmay, T., S112

Damann, K. E., S14, S17

Damicone, J. P., S17, S88, S128

Damrongkool, P., S96

Damsteegt, V. D., S36, S46, S9, S132

Danielsen, S., S17

Danielson, D. J., S38

Danks, C., S43
D’Arcy, C. J., S114

Darjean, D. H., S17

Dargent, R., 915

Da Rocha, A. B., S17

D'Ascenzo, M. D., S73

Daub, M. E., 139

Daughtrey, M., S115

Daugrois, J. H., S18

Daus, A., S20

Davidson, C. R., S131

Davière, J.-M., 1279

Davis, A., S18

Davis, E. L., S28, S82, S86

Davis, J. M., S104

Davis, J. R., S118

Davis, M. J., S18, S23

Davis, R. E., S5, S18, S39

Davis, R. F., S18, S84

Davis, R. M., S2, S68, S99, S121

Dawson, W. O., S2, S3, S30, S52, S69, S91, S92

Deahl, K. L., S4, S19

Dean, R. A., 851, S14, S40, S41

de Arruda, M. C. C., 758

De Ascensao, A. R. D. C. F., 1173

de Assis Filho, F. M., 1233

de Barros, E. G., 758

DeBiasio, L., S19

De Cal, A., 260

de Ceuster, T. J. J., S43

Dechamp-Guillaume, G., 915

Dedryver, C. A., 860

Défago, G., S19, S20

DeLittle, J., S85

Delserone, L. M., S59

de França, G. E., S10

Dehbi, L., 45

de Jensen, C. E., S22

Delfosse, P., 537

DeLittle, J., S85

Delserone, L. M., S59

Dendryphion penicillatum

-mycoherbicide for poppy diseases, 691

-on poppy, infection and disease, 699

Deng, T. C., S47

Deng, W.-L., S63, S64

Deom, C. M., 214, S125, S128

DePriest, P. T., S133

Derkson, R. C., S43

Derr, J. F., S36

Dery, P. D., S65

Descalzo, R., S99

de Silva, A., S18

Desjardins, A.A E., S96

De Souza, W., 1032

Despins, T., S48

Desvoyes, B., S53, S59, S112

de Van Kerckhove, G. A., S79

de Vries, P. M., 1358

de Wet, J., S18

De Wolf, E. D., 108, S19

Diab Al-Arab, H. G., S19

Dias, B. B. A., S23

Diagnostic

—decentralized, in field, S112

-education program: distance, S112; in Louisiana, S113

-ImmunoStrip test, S103

-in industry, S112

— pests via the Internet, S84

— program evaluation, Florida, S113

- sample tracking and reporting system, in North Carolina, S113

Dias, F. A., 1032

Dicliptera sexangularis, biological and molecular properties, 723

Dickson, D. W., S123, S128

Didymella spp.

-D. bryoniae: on cucumber, acquired resistance,

S17; on melon, resistance to benomyl, S101; world collection, AFLP analysis, S41

-D. rabiei, on chickpea, management by resistance and fungicides, 834

Dieguez-Uribeondo, J., S118

Dietzgen, R. G., 921, 1295

Dill-Macky, R., S60

Dimarco, J. N., S19

Ding, X. S., S12, S19, S82

Dinoor, A., 1256

Diospyros kaki, black spot, gibberellin treatment, resistance effect, 1256

Di Primo, P., 751

Dirac, M. F., S118

Discula spp.

-D. destructiva: on Cornus florida, in Alabama, S35; on dogwood, multiple dsRNAs, S66

-D. umbrinella, on Quercus spp., genetic diversity, S15

Disease clinic, survey results, USA, S113

Disease detection

—aerial remote sensing methods, S103

-microarray technology, analysis, S103

Disease diagnosis

- cold field emission scanning microscopy, S43

—DNA arrays, multiplex detection, S103

-rep-PCR genomic fingerprinting method, S50

Disease management (see also Management)

-apple and watermelon disease-warning systems, weather data, S27

—epidemiology contribution, 1181

-fungal viruses, application, S124

- organic amendments and tarping for soilborne plant pathogens, 253

- technology implementation, S120

Di Terlizzi, B., 1330

Dobinson, K. F., 1011

Dodds, J. A., S118

Doebley, J., S95

Dolja, V. V., S91, S108

Dominiak, J. D., S131

Donaldson, G. K., S110

Donaldson, R., S13

Dong, H., 801

Donzelli, B., S20

Doohan, F. M., 666

Dorokhov, Y. L., S111

Dorrance, A. E., S18, S78, S93

Doudrick, R. L., S104

Douhan, G. W., S20, S118

Doxtader, D. C., S45

Drayton, M. N., S50

Driever, G. F., S56

Droby, S., S20

Druffel, K., S45

Dry, I., S24

Dubery, I. A., 1173

Dubey, T., S20

Dudley, J. W., 1018

Duffus, J. E., S57

Duffy, B., S19, S20

Dufour, J., S21

Dugan, F. M., S20

Duick, J. W., S126

Duncan, G. H., 1153

Duncan, J., S20, S70

Duncan, S., S7

Duniway, J. M., S102

Dunkle, L. D., 486

Dusabenyagasani, M., S21

Duthie, J. A., 1120

Dutra, P. M. L., 1032, S89

Dwinel, L. D., S104

Dyer, A. T., 565

Eaker, T. H., S84

Eastwell, K. C., S117

Eayre, C. G., S21

Ebelhar, S. E., S3

Echeverri, C., S3 
Ecosystem, epidemiology, research questions, 1181

Eddleman, C. D., S121

Education, Koch's postulates, usefulness, S114

Edwards, M. C., S36

Egel, D. S., S100

Ehrlich, K., S107

El-Allaf, S. M., S21

El-Assiuty, E. M., S68

Ellis, L. E., S21

Ellis, M. A., S21, S115

Elm

-Dutch elm disease: lessons, S114; past and future prognosis, S98

-Ophiostoma spp., genomic mapping, S21

Emerson, R. W., S53, S71

Emery, K. M., S126

Endothia gyrosa, on Eucalyptus, new taxon, S80

Enebak, S. A., S22, S71

English, J. T., S7, S48

Ens, W., 505

Enterobacter cloacae, catabolic capability, in cucumber and pea spermosphere, S65

Entomosporium mespili, on saskatoon, temperature and leaf wetness effect, S36

Epidemics, spatial statistics, spore dispersal gradient quadrat size and shape, 738

Epidemiology

-description for $20^{\text {th }}$ century, 1181

- population biology and disease management, 1181

—population genetics, molecular markers, 1181

Errata

—vol. 89, no. 5, 1999, 1182

—vol. 89, no. 6 (suppl.), 1999, 103

- vol. 90, no. 5, 2000, 1056

—vol. 90, no. 6 supplement, 2000, 928, 1181, 1182

—vol. 90, no. 8, 2000, 1295

Erickson, M. L., S84

Erincik, O., S21

Erselius, L. J., 197

Ersoy, A., S6

Erwinia spp.

-E. amylovora: on apple leaves, detection, S121; on pear, viral EPS-depolymerase, control, 1263; on pomaceous flowers, water effect, 1352; streptomycin and oxytetracycline resistance, in Lebanon, S68; in Turkey, strain fingerprinting, S5

- E. chrysanthemi: genomic approach, S108; Hrp pathogenicity island, S66

$-E$. herbicola, on gypsophila, virulence protein expression, S22

Erysiphe graminis, on wheat, spore efficacy and host genetics, 1300

Escobar, D. E., S73

Escriu, F., 480, 1068

Eshel, D., 751, 1256

Esker, P. D., S21, S22

Esnard, J., S114

Essenberg, M., S59

Estes, B. L., S22

Eucalyptus spp.: bacterial blight and dieback, in South Africa, S16; Endothia gyrosa, South Africa, S80

-E. grandis, diseases in Uganda, $\mathrm{S} 67$

Eun, A. J.-C., 269

Euphorbia millii, flower blight, $\mathrm{S} 1$

Eutypa lata, on grape

—asexual spread, S120

-temperature, S66

-yield components, S11

Evans, P., S118

Evans, T. A., S6, S114, S131, S132

Everitt, J. H., S73

Everson, D. O., S118

Everts, K. L., S22

Eweida, M., S79
Ewing, E. E., S68

Extension

—diagnosis problems, S116

-health management principles, ornamental plants, S115

—history in Louisiana, S115

- plant doctor definition, S115

Eyal, Z., 297, 601

Eyestone, E. J., S22, S111

Ezra, D., S22

Fabritius, A.-L., S119

Fairbrother, T. E., S50

Fakhouri, W., S22, S55

Fakhoury, A. M., S23

Fakhr, M. K., S23

Falk, B. W., S67, S72, S91

Faria, J. C., S23

Farman, M. L., S55, S64, S75

Farnham, M. W., S41

Farkash, S., 1105

Farr, D. F., 691, S123

Farrall, L., S110

Farrell, R. L., S7, S34

Farris, N., S118

Faulk, K. N., S110

Fayad, A., S23, S132

Federal Insecticide, Fungicide, and Rodenticide Act

- pesticide registration and cancer guidelines, S116

—policies, safety, and risk, S116

- reregistration eligibility decision, update, S116

- transition strategies, crops at risk, S116

Felix-Gastelum, R., 1188

Felts, D., S53

Fenn, P., S38

Ferguson, G., S12

Fernandez, A., S67

Fernandez, G. E., S30

Fernando, W. G. D., S36

Ferrand, K. H., S81

Ferrand, S. K., S72

Ferree, D. C., S21

Ferreira, S. A., S27

Ferrera-Cerrato, R., S123

Ferrino, F. J., S23

Ferro, J. A., S93

Ferwerda-Licha, M., S23

Fery, R. L., S76

Festuca arundinacea, brown patch, biocontrol with Stenotrophomonas maltophilia, 384

Fettinger, J. C., S56

Fichtner, J. C., S56

Ficke, A., S24, S26

Finckh, M. R., 621

Fir, needle blight syndrome, fungicides for, factors, S117

Fischer, M., 967

Fish, W. W., S24

Flake, J. W., S119

Flanagan, S. R., S87

Flat apple virus, Cherry rasp leaf virus compared to, molecular detection, S38

Fletcher, J., 716, S6, S18, S63, S113, S126

Fletcher, R. S., S73

Flier, W. G., S31

Flores-Estevez, N., S24

Flowers, J. L., S24

Foglia, R., S24

Folimonov, A., S12

Fomitiporia punctata, on grape, esca symptoms, 967

Fonseca, D., S124

Forbes, G. A., 197

Forests

-management policy and diseases, S97

-pathology, concept evolution, S98

- pathology in North America, 20 $0^{\text {th }}$ century issues, S98

-tree diseases, perspectives and challenges, S98

Förster, H., 171, S2, S119

Forster, R. L., S24

Forsythe, D. A., S104

Foulds, I. V., S52

Fouts, D. E., S24

Fox, R. D., S43

Fraedrich, S. W., S104

Fraile, A., 480

Francis, D. M., S93

Francl, L. J., 108, S2, S19

Frankliniella spp.

$-F$. fusca, on peanut, nematode effect on epidemiology, S26

-F. occidentalis, Tomato spotted wilt virus vector, 454

Frantz, G., S100

Fraser, D. E., S25

Frederick, R. D., 951, S25

Freeman, N. D., S25

Freeman, S., 608

Freitas-Astua, J., S25

French, R., S25, S33

Friesen, T. L., S25

Fritz, L. K., S42

Fritsch, C., 460

Fry, W. E., 78, 197, 987, 1181, S31, S50, S68, S73, S94

Fuchs, Y. S46

Fujii, Y., 285

Fujita, Y., S77

Fukui, R., S78

Fulbright, D. W., 38, S51, S97

Fuller, K., S25

Fumigants

-irrigation application, S102

-methyl bromide, trends, S102

-soil, methyl bromide alternatives, S102

-soil injection, emission reduction, S102

Fumigation, root-knot nematode, dichloropropene, S128

Funderburk, J. E., S26

Fungicides (general) (see also Fungicides, specific)

- acetates and salt effects on plant pathogenic fungi, S75

-Ascochyta blight of chickpea, postinfection applications, 834

-microbioassays for, in National Center for Natural Products Research, S83

-pathogen metabolite, disease control, S53

- pathogen resistance, regulatory aspects, S100

- postharvest decay, stone fruit crops, preharvest, S2

- potato late blight, mating type and changes induced by fungicides, 1201

-registration update, minor-use, S77

-resistance: management strategies, S100; population aspect, S100; selection pressure and dose heterogeneity, model, 333

-roses, foliar diseases and resistance, S65

Fungicides (specific) (see also Fungicides, general)

-BAS $500 \mathrm{~F}$ : broad-spectrum, fruit, vegetable, and field crops, S5; field crop application, S38

- carboxin, Ustilago nuda resistance gene, 179

- dicarboximide, Botrytis cinerea resistant to, fitness, 1246

-lysozyme, from chicken egg white, effect on fungi, S26

-mefenoxam, Phytophthora capsici insensitive to, 396

-Sovran: apple IPM program, S5; performance and management, S130; performance and management guidelines, S134

-strobilurin: biological characterization, S74; broad-spectrum, S3; properties and performance, S28; turfgrass disease control, broad- 
spectrum, S53

-thiophanate-methyl and vinclozolin, Botrytis cinerea sensitivity, genetic analysis, 851

Furman, L. A., S26

Fusarium spp.: on faba bean and Orobanche sp., metabolite toxicity, S32; genomics, germ plasm conservation, S96; on melon, fruit rot, S24; populations distinguished with AFLP, $\mathrm{S} 46$

-F. avenaceum, on lisianthus, airborne dispersal, sampler method, S128

$-F$. culmorum, on wheat, antifungal activity of extracts, 666

$-F$. equiseti, trichothecene from, nematode antagonism, S56

-F. graminearum: on barley, quantitative trait loci, 1079; on wheat, protein constructs, suspension cell assay, S35; on wheat, situation in Iran, 103; on wheat, survival and inoculum in residue, $\mathrm{S} 60$

-F. moniliforme, fungicide, growth effect, S87

$-F$. oxysporum: on banana, race 4 resistance, 1173; on basal, seed treatment, S2; on chickpea, epidemics and yield loss, 1269; gene genealogies and AFLP analyses, complex, 891; on melon, Impala transposition, pathogenicity, 1279; on opium poppy, Nep1 protein, biocontrol, 812; in soil, control by organic amendments and tarping, 253; soil fumigation for, synergy of combinations, S119; soil treatments and solarization, 751; on sugar beet, biological seed treatment, S119; on tomato and basil, airborne conidia, 1322; on tomato, pseudomonad and benzothiadiazole effect, S22; transformation, pathogenicity gene tagging, S54; transformation, phytotoxic protein Nep1, S4

-F. sambucinum, on potato, inhibition by salt, S51

-F. solani: on caladium, fungicide and hot water treatment, S123; on soybean, detection by DNA and PCR, S46; on soybean, herbicide effect on glyphosate-tolerant plants, 57; on soybean, molecular differentiation, rDNA sequence, 491; on soybean, transmission, S4

$-F$. subglutinans, on longleaf pine seed and seedlings, losses, S71

-F. verticillioides, Aspergillus flavus and insect interaction, on corn, Africa, 276

Gabel, B. R., S110

Gadoury, D. M, S24, S26, S35

Gaeumannomyces spp.

- disease diagnosis, S97

-on turfgrass, patch disease, S97

Gagné, S., 45

Galeffi, P., 1337

Galibert, F., S92

Gally, T. A., S26

Gal-On, A., 467

Gamliel, A., 751

Gan, J., S102

Ganoderma lucidum, medicinal properties, pathogenesis, S14

Gao, W., S26

Gao, Y. C., S26

García-Arenal, F., 480, 1068

Garcia Corral, M. R., S16

García-Espinosa, R., S123

Garcia-Lepe, R., 260

Garcia-Pedrajas, M. D., S28

Gardan, L., 636

Gardner, M. E., S27

Gardner, R. G., S25

Garnsey, S. M., S2, S91, S92

Garrett, K. A., 1307, 1313, S27

Garrido-Ramirez, E. R., 1224, S87

Gaskill, D. A., S27

Gaspin, C., S93
Gatch, E. W., S27

Gates, R. N., S84

Gaudet, D. A., S48

Gautheron, N., 1279

Geering, A. D. W., 921, 1295

Geider, K., 1263

Geils, B. W., 1073

Geiser, D. M., SS54, S87, S96

Gelie, B., 915

Gembeh, S. V., S27

Gene cloning, $R$ genes from arabidopsis and soybean, evolution, S110

Genetically modified crops

—dual market system, process vs. product, S95

—panacea or apocalypse?, S95

—risk assessment, in agriculture, S103

Genomics, advances, resource conservation, S95

Gera, A., 340, S70

Gergerich, R. C., S49, S82

Gerlinger, C., 1279

German, T. L., S22, S84, S111

Gesalman, C. M., S116

Gessler, C., S109

Ghabrial, S. A., S31

Gibberella spp.

- G. fujikuroi: antimicrobial compounds from, detoxification, S27; on maize, fumonisin and ear rot, S96

-G. zeae: AFLP linkage map, S40; ascospore discharge, mechanism, S86

Gibson, D. M., S72

Gibson, L., S85

Gibson, R. W., 1250

Gierz, G., S121

Gilbertson, R. L., 1224, S5, S35, S39, S74, S75, S87

Gildrow, F. E., 1153

Gilman, E. F., S106

Gilreath, J. P., S66

Giroux, M., S43

Gitaitis, R. D., 191, S130

Giunta, G., 1337

Glasheen, B. M., S27

Glaux, C., 636

Gleason, M. L., S27, S59

Gleddie, S. C., S96

Glenn, A. E., S27

Glenn, D. L., S132

Glick, D. L., S28

Globodera rostochiensis, on potato, G. pallida comparison, infestation foci, 647

Gloeophyllum trabeum, transplasma membrane redox system, S62

Glozer, K., S69

Goates, B. J., S28

Goeke, S. C., S28

Goellner, M., S28

Goffeau, A., S92

Goffinet, M., S24

Gold, R. E., S5, S28, S53, S130

Gold, S. E., S28, S126

Goldbach, R. W., 183, 454

Goley, E. D., 1126, S46, S77, S132

Golino, D. A., S28

Gomez, V., 1246

Gonsalves, C. V., S29

Gonsalves, D., S14, S27, S29, S52, S91, S109, S112

González, B., S26

Gonzalez, C. F., S51, S115

González, E., S29

Gonzalez, M. S., S122

Goodell, N. C., S29

Goodman, M., S95

Goodman, R. M., 657, S79

Goodwin, S. B., S29, S42

Gorbet, D. W., S26, S83, S125

Gordon, D. T., S64

Gordon, S. H., S50, S80
Gordon, T. R., S8

Gotoh, S., 311

Gottwald, T. R., S29

Goud, J. C., S29

Gouzy, J., S93

Gowda, S., S2, S30, S69

Grabowski, M. A., S30

Gracia-Garza, A, J., S30

Grafton-Cardwell, E., S72

Graham, J. H., S29, S30

Graham, T. L., S6

Gramacho, K. P., 1005

Grape

-bacterial blight, diagnosis, comparison of methods, S69

-decline: in California, S28; microbial community in Pennsylvania, S31

- new virus from, molecular characterization, S88

- powdery mildew: quinoxyfen effect, S32; Quintec fungicide for, S54; relative humidity, S12

—replant problem, bioassay, S83

-rupestris stem pitting, detection and molecular biology, S52

-wood decay, esca symptoms, identification, 967

Grapefruit, postharvest decay, dynamics of antagonists, 1217

Grapevine berry inner necrosis virus, on Nicotiana occidentalis, Apple chlorotic leaf spot virus relation, 311

Grapevine leafroll virus, transgenic resistance, S91

Grass, storage, fungi in seeds, S20

Grau, C. R., 657, 875, S37

Graves, A. S., S132

Graves, W. R., S1

Gray, F. A., S119

Gray, S. M., S30, S45

Green, E. A., S32

Green, H., 1049

Green, J. F., S30

Greene, S. E., S30

Greenland, A., S68

Gregor, J., S92

Grgurina, I., S70

Gremmeniella spp., on conifers, DNA sequences, host-pathogen co-evolution, S21

Griep, R. A., 183

Griffey, C. A., 1131

Griffith, M., 354

Griffiths, H. M., S30

Grillo, L. A. M., 1032

Grinstein, A., 751

Gritsenko, M. A., 1137

Gronenborn, B., 629

Gross, D. C., S48, S70

Groundnut rosette assistor virus, sequence diversity, 214

Grove, G. G., S31

Groves, C. L., S31

Groves, C. T., 1201, S65, S82

Grumet, R., S78

Grünwald, N. J., S31, S94

Grybauskas, A. P., S12

Gu, H., S31

Gu, Y.-H., 114, S31

Gubler, W. D., S53, S66, S84, S120

Gudmestad, N. C., S1

Guerber, J. C., 1396

Guerra, D. J., S20

Guerri, J., 134, S3, S67

Guest, D. I., 775

Guggenheim, R., S67

Gugino, B. K., S31

Guignardia bidwellii, myclobutanil and azoxystrobin effect on, post-infection, S35

Guilhabert, M. R., S31 
Gumpertz, M. L., 148

Gumpf, D. J., S72

Guo, B. Z., S32

Guo, L., S111

Gustafson, G. D., S32

Gustafson, H. L., S65

Gutierrez, H. E., S32

Guzman, P., S35

Gwinn, K. D., S30

Hadwiger, L. A., S42

Hagan, A. K., S32, S65

Hagenaar-de Weerdt, M., 867

Haikal, P. R., S2, S32

Hajimorad, M. R., S32

Halbrendt, N. O., S35

Hale, F. A., S84

Hall, J. S., S33

Hall, R. B., 1039

Hallmann, J., S72

Halloin, J. M., S33, S39, S55

Halsey, L., S113

Halsey, M. E., S33, S63

Ham, J. H., S33

Hamblin, A. M., 292

Hamelin, R. C., 1073S21

Hamer, J., S47

Hamer, L., S47

Hamilton, A. J., S112

Hamilton, D., S112

Hammerschmidt, R., S17, S49, S80, S99

Hammond, G. A., S75, S134

Hammond, R. W., S33, S88

Han, D. Y., 327, S33

Hanada, K., 422

Handelsman, J., 657

Hanna, L., S68

Hanna, W. W., 1169

Hansen, D. R., S33, S44

Hanson, L. E., 248, S34

Hao, J. J., S34

Harbaugh, B. K., S123

Hardman, J. M., S5

Harikrishnan, R., S34

Harman, G. E., 72, S20, S109

Harp, T. L., 1396

Harrington, M. A., 1011

Harris, D. C., 1367

Harris, L. J., S96

Harrison, N. A., S30

Hartin, R. J., S8

Hartman, G. L., 491, S27, S44, S46, S54

Hartman, J. R., S24

Hartung, J. S., S13, S37, S62, S108

Hartzog, H. M., S34

Harveson, R. M., S34

Harvey, T. L., S70

Hassanein, A. M., 1182

Hatzios, K. K., S71, S133

Hau, B., 1269

Haugen, L., S11

Hausbeck, M. K., 38, 396, S51

Hauser, S., 460

Hawes, M. C., 1239

Hawkins, O., S17

Hay, F. S., S61

Hay, R. T., 1153

Hayes, C. K., 72

Haymes, K., S20, S34, S70

Haynes, K. G., S62

He, S. Y., S49

Healy, F. G., S47

Heaney, S., S57

Heath, M. C., S52

Hein, G. L., S34

Heinz, R. D., S16

Heist, E. P., S126

Held, B. W., S7, S34

Heldreth-Fleming, K. M., S133
Heller, W., S8

Helm, J. H., 94

Henick-Kling, T., S26

Henriquez, J. L., S119

Henriquez, M. A., S49

Hensley, D., S84

Henry, M. J. (Indiana), S32

Herbicides

—disease resistance induced by, mechanisms, S99

- glyphosate, root rot fungi affected by, S99

—nematode biocontrol, relationship, S99

- soybean, glyphoste resistance and root disease, S99

- soybean sudden death syndrome, glyphosatetolerance, 57

—-synergism with weed biocontrol agents, S98

Herlach, T. (New York), S11

Herlache, T. C. (Wisconsin), S34, S35

Hermoso de Mendoza, A., 134

Hernandez, N. A., S35

Herpetomonas spp., plant parasites, ectophosphatase activities, 1032

Herranz, M. C., 1330

Herrbach, E., 460

Herrero, S., 139

Herron, C. M., S35

Herselman, L., 1026

Hert, A., S122

Hess, D. E., 1169

Hess, N. J., S35

Hesterberg, D. L., S23

Heterobasidion annosum

—on ponderosa pine, secondary metabolism, S8

- trenching and stump removal, S57

Heterodera spp.

-H. glycines: male:female ratios, host resistance effect, S16; on soybean, hatching signal, S61

$-H$. schachtii, on Swiss chard, suppressiveness transferred, 401

Hevea brasiliensis, brown bast, in China, S87

Hickey, K. D., S35

Hicks, D., S20, S34, S70

Hicks, N., S115

Hiebert, E., S23, S25, S123

Higgins, V. J., S52

Highland, H. B., S101

Hilburn, K. L. B., S35

Hilf, M. E., S92

Hill, J. H., S32, S101

Hill, J. P., S117

Hillman, B. I., S24, S27

Himmler, G., 1337

Hinkley, S. F., S1

Hinton, D. M., S4, S87

Hiradate, S., 285

Hiremath, S. T., S5, S75, S88

Hirsutella rhossiliensis, nematode parasite, use in biocontrol, 498

Hishimonoides sellatiformis, mulberry dwarf phytoplasmas, identification, in genital organs and eggs, 909

History, plant pathology in Virginia, 110-year chronology, S133

Ho, H. H., S87

Hoagland, R. E., S98

Hoffman, L. E., S35

Hohl, H. R., 197

Hohn, T., S57

Hoinacki, B., S36

Hoitink, H. A. J., 327, S36, S43

Hollier, C. A., S113, S114, S115

Hollowell, J. E., S72

Holmes, G. J., S119

Holt, J., 85

Holtslag, Q. A., S36

Honeycutt, E. W., S36, S126

Hong, C. X., S36

Hong, J. S., 1390
Hoover, R., S126

Hopf, A., S38

Hopkins, D. L., S126, S129

Hopkins, M., S13

Hord, M., 1098

Horino, O., 415

Horken, K. M., S36

Horst, R. K., S75

Hosta spp., Fusarium root and crown rot, cultural practices, $\mathrm{S} 129$

Hou, R. F., 228

Hou, Y. M., S12

Howd, D. S., S9, S36

Howell, C. R., 248, S34

Howell, W. E., S38

Hraber, P. T., S109

Hsiang, T., 354

Hsu, F. S., S36

Hsu, H. T., 615, S82

Hsu, Y. H., 615, S82

Hu, J. S., S52, S71, S92

Huang, H. S., 37

Huang, Q., S37

Hubbard, J. C., 305, S7, S34

Huber, D. M., S37, S77

Hubner, J., S134

Hudson, R. A., S101

Hughes, G., 788. S120

Hughes, M. G., S103

Hughes, R. H., S53

Hughes, T. J., S37

Huisman, O. C., 305, S118

Hulbert, S. H., S59, S108

Hunger, R. M., S57

Hunt, R. S., 1073

Hur, J. H., S39, S42

Hussey, R. S., S82

Hutchinson, C. M., S119

Hydrogen peroxide, fungal growth and penetration restricted by, S52

Hyland, J. R., S35

Hymowitz, T., S27

Hypericum spp.

-H. edisonianum, Sphaeropsis knot, S79

$-H$. perforatum, plant defense, hypericins, S72

Hypersensitivity

- harpin, gray mold, and fruit rot diseases, S62

—nitric oxide synthase inhibitor, genetic screen, S134

—Ralstonia solanacearum, factors, S13

Ibañez, A., 407

Ice nucleation, snow mold role, 354

Idris, A. M., 546, S10, S37, S122

Ieki, H., 1209

Illman, B. L., S37

Innes, R. W., S110

Inoue, H., S37

Innovation

—art of science, tale of two cultures, S113

-creativity, S113

—research environments, luck and design, S113

-teaching, rewards and dangers, S114

Inoue-Nagata, A. K., 454

Integrated pest management

—Distance Diagnostics, in Georgia, S127

-implementation, S99

— peanut, spotted wilt, factors, S99

- tomato, Florida, S100

Ipomoea nil, Sweet potato feathery mottle virus and Potato virus X, systemic spread, 944

Irish, B. M., S16, S37

Irwin, M. E., 788

Isakeit, T. A., S10, S38, S101

Isatis tinctoria

—biological control, rust, S33

-rust as a bioherbicide, S44

Ishihara, J., S77

Ishimaru, C. A., S93, S109 
Ito, T., 311

Ivanov, P. A., S111

Ivors, K., S38

Izadpanah, K., S38

Jackson, E. W., S38

Jacobi, V., 1073

Jacobs, K. A., S38

Jacobsen, B. J., 368, S101

Jacques, M.-A., S101

Jaffee, B. A., 498

Jaime-Garcia, R., 1188

James, D., S38

James, T. W., S38

Jan, F.-J., S14

Jang, H. Y., S39

Jang, J. Y., S39

Janisiewicz, W. J., 1196, S39, S46

Jarret, R. L., S13

Jarvis, B. B., S1

Jatropha mosaic virus, on weed and cultivated hosts in Puerto Rico, S122

Jayawardena, T., S132

Jeffers, S. N., 851, S126, S127, S129

Jeger, M. J., 576

Jelkmann, W., S67

Jellison, J., S25, S62

Jennings, J. C., 691, 699

Jensen, D. F., 1049

Jensen, G. D., 1073

Jensen, R. G., S10

Jensen, S. G., S59

Jeong, K.-S., S13

Jia, Y., S110

Jiang, H., S39

Jiang, Z., S39

Jiménez, I., 1098

Jiménez-Díaz, R. M., 1269

Jin, Y., S88

Johal, G. S., S99

Johnson, B. J., S1

Johnson, C. S., S39

Johnson, D. A., 220

Johnson, D. J., S33, S39

Johnson, D. W., 657

Johnson, E. M., 362

Johnson, K. B., 1285, S101

Johnson, L., 973

Johnson, R. D., 973

Jomantiene, R., S39

Jones, A. L., S49, S70, S100

Jones, D. R., 884

Jones, J. B., 208, S74

Jones, M., S94

Jones, P., 928

Jones, V., S110

Jones, W., S88

Joobeur, T., S40

Judelson, H. S., 1112, S119

Jurgens, J. A., S40

Jurgenson, J. E., S40

Jurjevic, Z., S40, S129

Jurkevitch, E., 608

Jurkowski, G. I., S40

Juzwik, J., S55

Jwa, N. S., S40, S59

Kabelka, E., S93

Kadooka, C. Y., S78

Kahlke, C. J., S40

Kahn, D., S93

Kaiser, W. J., S45

Kaku, H., 415

Kameya-Iwaki, M., 422

Kanda, K., 944

Kanematsu, S., 1209, S40

Kang, S., S26, S38, S54, S59, S64, S87

Kang, Z., S22

Kannwisher-Mitchell, M. E., S66
Kanotra, S., S132

Karasev, A. V., S3, S52, S92

Karpova, O. V., S111

Karr, A. L., S48

Karuppaiah, P., S41, S111

Karyeija, R. F., 1250

Kassemeyer, H.-H., S67

Kastelein, P., 1358

Katagi, C., S12

Katan, J., 529, 751, 1322

Katan, T., 529

Kataoka, T., 1060

Kato, H., 944

Kato, K., 422

Kaufman, H. W., S83

Kawakita, H., 909

Kawasaki, J., 1060

Kawase, M., S77

Kazmar, E. R., 657

Kearns, B. D., S71

Keel, C., S20

Keeler, L. C., S32

Keeling, B., S1

Keen, N. T., S93

Keener, H. M., S36

Keinath, A. P., S41

Keith, L. M., S41

Keith, R. C., S41

Kekarainen, T., 437

Keller, H. J. H. G., 183

Kellerhals, M., S109

Kelman, A., 564

Kema, G. H. J., S29

Kemerait, Jr., R. C., S41

Kenerley, C. M., S79

Kent, A. D., S34, S41

Kers, J., S41

Kerschbaumer, R. J., 183, 1337

Khan, A. (California), S84

Khan, A. J. (Sultanate of Oman), 928

Khan, N. I., S42, S69

Kheyr-Pour, A., 629

Kim, C. Y., S42

Kim, D. H., 243, S82, S119

Kim, E. S., S42

Kim, H. R., S49

Kim, J. S., S42

Kim, K. S., S28, S49, S77, S82

Kim, M.-S., S42

Kim, S. (Pa.), S87

Kim, S. O. (Korea), S42

Kim, W.-S., 1263

Kim, Y. S., 1390

King, P. S., S124

Kingsley, M. T., S42

Kinloch, B. B., S97

Kinneer, K. L., S133

Király, L., S16

Kirk, W. W., S74

Kirkpatrick, B. C., S17, S31, S69

Kirstgen, R., S3

Kisha, T. J., S42

Kislan, M., S92

Kistler, H. C., S79

Klessig, D. F., S46

Kliejunas, J. T., S57

Kling, J. G., 276

Kloepper, J. W., S123

Klopfenstein, N. B., 1039, S42

Klosterman, S. J., S42

Knight-Slater, D. F., S66

Knorr, D. A., 951

Knudson, D. L., S93

Ko, K., S56

Kobayashi, D., S58

Kobbeman, K. E., S43

Koch, D. W., S119

Kodama, M., 973

Koehle, H., S74
Koenig, R., 1098

Koganezawa, H., S68, S77

Kohmoto, K., 595, 973

Kohn, L. M., 514

Koike, S. T., S7, S15, S16, S34, S56

Koiwa, H., 944

Kokalis-Burelle, N., S2

Kolb, F. L., 1043, S4

Koller, B., S109

Köller, W., S3, S82, S100

Kolmer, J. A., 427, S94

Kong, P., S67

Korimbocus, J., S43

Kormelink, R., 183

Korolev, N., 529

Kosman, E., 601

Kosted, P., S43

Kothera, R. T., S41

Kousik, C. K., S66

Kousik, C. S., S43, S74

Kraft, J. M., 1137

Kraus, G., S61

Krause, C. R., S43

Krause, M. S., S36, S43

Kremser, J. J., S6

Krentz, S., S26

Kresovich, S., S95

Kreuze, J. F., 1250

Krishnamurthy, K., S43

Kristjansson, G., S48

Kroon, L. P. N. M., 891

Kropp, B. R., S33, S44

Kropp, M. J., S15

Krupinsky, J. M., S17

Kubelik, A. R., 819

Kubisiak, T. L., 1039

Kucharek, T. A., S41, S113, S126

Kudzu, diseases in China, S39

Kuhajek, J. M., S83

Kull, L. S., S44

Kumm, J., S93

Kumm, S., S84

Kuo, Min-Hao, S70

Kurnik, B., S44

Kurtzweil, N. C., S37

Kusaba, M., 1060

Kuti, J. O., S32, S55

Lablab purpureus, protein from, Aspergillus flavus inhibition, S23

Laccaria bicolor

-acetyltransferase and mutualistic symbiosis, S88

-malate synthase, symbiosis-regulated, S5

—on red pine, symbiosis expression, $\mathrm{S} 75$

Lacey, M. J., S44

Lacy, G. H., 208, S75, S133, S134

Laguna, I. G., S40

Laguna, R. J., S44

Laigret, F., 134

Lalancette, N., S26, S44

Lamb, J. W., 1153

Lamers, J. G., 253

Lamondia, J. A., S44

Lamour, K. H., 396

Lancaster, M. E., S119

Landry, A. D., 723

Lane, C. R., 973

Lane, L. C., S45

Langham, M. A. C., S45

Langston, D. B., Jr., 191, S130

Lannou, C., 1300

Lapeyre, F., 884

Lapitan, N. L., 1079

Larkin, R. P., S45

Laroche, A., S48

Larsen, R. C., 1137, S45

Larson, K., S120

Latin, R., S100 
Latour, X., 636

Lawrence, D. M., S27

Lawrence, G. W., S51

Lawson, C., 1043

Lazarovits, G., S16, S41, S73

Leach, J., S4, S108

Lease, R., S87

Leavitt, G. M., S45

Leclercq-Le Quillec, F., 860

Lecoq, H., 629

Lecours, N., 1073

Lee, D. R., S29

Lee, F. N., 1396

Lee, H. K., S45

Lee, H.-I., S13

Lee, L., S45

Lee, M.-W., S45

Lee, T. Y., S6

Lee, U., 1390

Lee, Y.-H., 1162, S40, S42, S54, S59

Legard, D. E., S7, S46, S53, S79, S86

Leggett, G. W., S60

Legrève, A., 537

Legumes, rhizosphere, nematode population and enzymes, Alabama, S124

Lehman, J. S., 390, S82

Lehman, L. J., S50

Leininger, T. D., S11, S105

Lemaire, O., 460

Leonard, K. J., 565

Leopold, L., S12

Le Quéré, D., 45

Leptodontium elatius, on apple, temperature and relative humidity effect, 362

Leptosphaeria maculans, on Brassica napus, resistance and potential durability, field method, 961

Leslie, J. F., S40, S46, S68

Letter to the editor

-molecular tools, contamination and error, 565

-plant pathogen population, recombination and migration rate, 320

-plant pathogen population, recombination and migration rate, reply, 324

- pseudomonads and xanthomonads, proposed amended names, 208

-statistical measures, quadrat-based, disease incidence data, 568

-Xanthomonas spp., taxonomy synopsis, 677

Lettuce

- downy mildew: disease forecast, 67 ; survival factors of sporangia, 827; warning system, temperature, S85

-drop, novel control, S85

-leaf drop, fungicide effects on, S49

- tombusviruses, characterization, S56

Lettuce infectious yellows virus, replication and transmission, $\mathrm{S} 91$

Leung, H., S4

Leverentz, B., S46

Levesque, C. A., S99, S103

Levivier, S., 961

Levy, L., S46, S132

Levy, M., 486, S37, S93

Lewandowski, D. J., S2

Lewis, B. G., S65

Lewis, P. I., S100

Li, J., S126

Li, R. G., S46

Li, S., 491, S46, S54

Liang, H., S46

Liao, T. F., S47

Lichen, symbioses, algal switching, S133

Lillehoj, E. B., S107

Lim, C. K., S39, S42

Lim, P. O., 1390

Lin, S. S., 228

Lin, X., S108

Linde, C., S47
Linder-Basso, D., S24

Line, R. F., S14

Lipps, P. E., S19, S42

Litchi chinensis, anthracnose, fungicides, $\mathrm{S} 123$

Little, E. L., S69

Liu, B., 1396

Liu, H. Y., S57

Liu, J. Q., 427

Lo, C. T., S47

Lo, C., S47

Loboda, A., 505

Locascio, S. J., S66

Locke, J. C., S8

Lockhart, B. E. L., 120

Loke, J. B., S3

Lommel, S. A., S32, S111

Loper, J. E., S101

Lopes, A. H. C. S., 1032

Lorenz, G. (Germany), S3, S74

Lorenz, G. (Arkansas), S99

Lorenzo, A. B., S115

Loria, R., S47, S66

Lorito, M., S20

Lotrakul, P., 723

Louie, R., S64

Louws, F. J., S30, S47, S71

Lu, M., S47

Lu, S. E., S48, S70

Lu, Z.-X., S48

Lucas, W. J., S39, S75, S87

Luce, K. M., S48

Luckman, G. A., S48

Ludy, R., S61

Lum, B., S57

Lumsden, R., S53

Lundeen, P., S86

Luo, Y., S48, S49

Luongo, A. J., S95

Lupien, S. L., S20

Luster, D. G., S4, S46, S87, S132

Lydon, J., S48

Lynch, R. E., S32

Ma, Z., 1079, S8, S48, S49

MacDonald, W. L., S98

Macguidwin, A. E., S67

Mack, T., S50

Mackenzie, S., S110

Madden, L. V., 157, 576, 788, S19, S21, S56, S106

Magnaporthe grisea

-appressorium formation: antifungal compounds, screening system, 1162; genes and sequence analysis, $\mathrm{S} 14$

—-fenhexamid sensitivity, S82

- gene function analysis, S47

-hydrophobin gene, molecular characterization, S42

-parasexual recombinants, genetic analysis, S77

-population structure, in USA, S64

-on rice: cover photo, October; durable resistance, S94

-strobilurin effect on, S3

-telomere linkage, host-specific gene, S26

-on wheat, host species specificity analysis, 1060

Mahaffee, W. F., S69, S78

Mahuku, G. S., S49

Maize (see also Corn)

Maize

-aflatoxin contamination, insects and Aspergillus relation, $\mathrm{S} 32$

-Fusarium verticillioides, Aspergillus flavus, and insect interactions, in genotypes in Africa, 276

- gene identification, genomic approaches, S108

— germ plasm, genes for diversity, S95

- jackbean intercropping, enzymatic activity, S123 -mal de Río Cuarto, genome typing in Argentina, S40

- potryvirus from, novel in Israel, 505

- viral RNA and cDNA, transmission by inoculation, S64

Maize chlorotic mottle virus, gene translation and function, S69

Maize rayado fino virus, genomic sequence, analysis, S33

Malinoski, M. K., S106

Maliszewski, L. E., S134

Mallory, A. C., S127

Management (see also Disease Management)

- conifer nurseries, methyl bromide, S104

-crop diseases, biorational approach in California, S99

- fiber production, disease relation, $\mathrm{S} 105$

- hardwoods, bottomland in Southeast, S105

-invasive species, national strategy, S105

-northern hardwoods, S105

-remote sensing and prescribed burning, in Iowa, S60

—remote sensing, spectral reflectance, S103

-rotation and tillage practices, field crops, S100

- soilborne pests, vegetable production systems, S102

-wood fiber and tree health, S105

Man in 't Veld, W. A., 867

Manion, P. D., S12, S98, S105

Manisterski, J., 601

Mankau, R., S117

Manners, J. M., S83

Mansoor, S., S9

Manulis, S., S22

Manuscript preparation, author's guide, 7

Mao, W., S53

Maragos, C. M., S15

Maraite, H., 537

Marathe, R. M., S127

Marek, S. M., S49

Marie-Jeanne, V., 505

Markham, P. G., S9

Maroon, C. J. M., S49, S70

Martin, E. M., S49

Martin, F. N., 345, S102

Martin, G. B., S73

Martin, R. R., 474

Martin, S. B., S97, S126

Martin, T. J., S70

Martin-Duvall, T. M., S45

Martinez, T., S123

Martini, M., S13

Masumi, M., S38

Masunaka, A., 762

Matheron, M. E., S49

Mathre, D. E., S3

Matsuda, I., S76

Matten, S. R., S100

Matthews, B. F., S108

Mau, R., S92

Mauk, P. A., S119

Mavrodieva, V. A., S46, S92, S132

Mawassi, M., S2, S30, S69

Maxson, K. L., S49

Maxwell, D. P., S23

May, G., S68

Mayama, S., 1060

Mayer, R. T., S74

Mayhew, G., S92

Maymon, M., 608

Maynard, C. A., S46

Maynard, C. M., S105

Mayo, M. A., 1153

Mayton, H. S., 987, S50

Maziya-Dixon, B., 276

Mazzola, M., 114, S31, S102

McAdams, S. A., S110

McAlpin, C. E., S50, S80

McClure, S., S18 
McCoy, C. W., S30

McCoy, R. J., S50

McCracken, J. L., S127

McDonald, B. A., 324, 901, 1181, S47

cDonald, G. I., S42

McDonald, J. G., S50

McDonald, S., S50

McElreath, S. D., S74

McGawley, E. C., S114

McGiffen, Jr., M. E., S119

McGovern, R. J., S65, S122, S123, S124, S127, S128

McGrath, D., S61

McGrath, M. T., S50, S133

McGuire, R. G., 1217

McLaughlin, M. R., S50

McLean, K. S., S51

McManus, P. S., S80

McMeans, E., S51

McMichael, L. A., 921, 1295

McMillan, Jr., R. T., S1, S123

McMullen, R. M., S35

McNabb, H. S., Jr., 1039

McPherson, R. M., S125

McSorley, R., S127

Mecteau, M. R., S51

Medeiros, R. B., S84

Medicago truncatula, pathogens of, S79

Medina-Mora, C. M., 38, S51

Medina, V., S91

Medrano, E. G., S51

Mejia, J. F., S2

Melampsora medusae, on poplar, resistance and molecular markers, 1039

Melcher, U., S6, S52, S63

Melgarejo, P., 260, 1246

Mellersh, D. G., S52

Mellinger, H. C., S100

Mellon, J. E., S52

Meloidogyne spp.: on holly and boxwood, cultivar reaction, S84; on squash, fumigation and chisel comparisons, $\mathrm{S} 128$

- M. hapla, on pepper, USDA germ plasm collection, S76

$-M$. incognita: biological suppression, soil survey, S120; fungus parasite of, ultrastructure, S77; root tip exudates, species-dependent effects, 1239

-M. javanica, on tomato, essential oils for control, 710

Melon (see also Cantaloupe, Muskmelon)

-ethylene production, postharvest decay, S88

-Fusarium wilt: Impala transposition, pathogenicity effect, 1279; resistance gene Fom-2, S40

Melon yellow spot virus, new virus on melon, 422

Melouk, H. A., S14

Melzer, M. J., S52, S92

Meng, B., S52

Meng, X. Q., 875, S52

Menge, J. A., S74, S118, S119

Mentewab, A., 666

Mercier, A. K., S63

Meredith, W. R., S1

Meronuck, R., S22

Mertely, J. C., S46, S53

Messenger, B. J., S50

Metcalfe, R. J., 1345

Meyer, S. L. F., S53, S56

Meyer-Fernandes, J. R., 1032

Michailides, T. J., S8, S48, S49, S53, S56, S62, S73, S107

Michel, J. A., S127

Michelmore, R. W., S110

Michener, P. M., S53

Microsphaera pulchra, on dogwood, ascocarp development, S53

Migheli, Q., 1279
Mihail, J. D., S10, S11

Milgroom, M. G., 967

Miller, J. S., 220

Miller, M. E., S10, S24, S101, S123

Miller, P. K., S38

Miller, S. A., S85, S93, S109

Miller, S. P., S71

Miller, T. (Florida), 1005

Miller, T. C. (California), S120

Miller, T. C. (Summas Group), S53, S71

Miller, W. A., S111

Milus, E. A., S81

Mims, C. W., 843

Minz, D., 608

Mink, G. I., S38

Minogue, T. D., S6

Minsavage, G. V., S74

Mirabile, J., S53

Mirkov, T. E., S35

Mirocha, C. J., S55

Mitchell, D. J., 1079, S66, S73, S127

Mitchell, F., S18, S63

Mitchell, R., S88

Mitchum, B. D., S5, S53

Mitsuhashi, W., 909

Miura, E., S63

Miyagawa, H., S37

Miyajima, K., 415

Miyao, E. M., S68, S121

Mizubuti, E. S. G., 78, 987

Mmbaga, M. T., S54

Model

-Barley yellow dwarf virus, serotypes, 860

-disease-progress-curve and yield loss prediction, 788

—interplot interference, S27

-mathematical, helper-dependent virus complexes, 85

-Melcast, muskmelon and watermelon, S100

- pesticide resistance, dose heterogeneity and selection pressure, 333

— strawberry foliar diseases, analysis, 157

—virus disease epidemic, vectors, 576

Mohan, S. K., S54, S120

Moisan, A., S93

Momol, E. A., S54, S127

Momol, M. T., S26, S54, S113, S127

Monilinia spp., on almond and stone fruits, fungicides for, $\mathrm{S} 2$

-M. fructicola: on prune, secondary infection, S48; on prune mummies, survival in field, S48; on stone fruit, symptomless latent infection, California, S53; on stone fruits, detection in California, S8; on sweet cherry fruit, detection, 171

-M. vaccinii-corymbosi: on blueberry, phenology, 390; disease gradients, inoculum point sources, S125; population genetics, S82; pseudosclerotia, oversummering, S17

Monosporascus cannonballus

-ascospore germination, microbe-mediated, 248

-ascospores, germination, S119

- population dynamics, S82

Montenegro, V., S47

Moore, L. D., S115

Moore, L. W., S121

Moorman, F. E., S78, S81

Moorman, G., S87

Morales-Payan, J. P., S123

Mordecai, S., S103

Moreira, M. A., 758

Morelock, T. E., S16, S37, S44

Moreno, M., 1098, S57

Moreno, P., 134, S3, S67

Morgan, D. P., S53

Mori, M., 1182

Morley, L., S52

Morris, C. E., 636, S101

Morris, T. J., S25, S33
Morrison, R. H., S128

Motes, J., S17

Mougel, C., 460

Mourichon, X., 884

Moury, B., 522

Mulberry, anthracnose, phytotoxins, 285

Mullahey, J. J., S124

Mullins, E. D., S54

Mulrooney, R. P., S131

Mumford, R. A., 448

Mundt, C. C., 324, 1313, 1307

Munkvold, G. P., S27, S120

Murakami, J., 1060

Muriuki, J. G., S55

Murphy, J. A., S19

Murray, T. D., S20, S118, S119

Mushroom

- compost, fungal flora in, survey, S38

-natural products of, bacterial growth suppression, S58

-Trichoderma green mold: epidemiology, S131; factors, S6

Muskmelon: (see also Cantaloupe, Melon): Fusarium wilt, botanical extracts for control, S8

Mycosphaerella spp.

-M. eumusae, on banana, new disease, 884

$-M$. fragariae, on strawberry, temperature and leaf wetness effect, 1120

-M. graminicola: DNA fingerprint probe, S29; population, recombination and migration rate, letter to editor, 320; population, recombination and migration rate, letter to editor, reply, 324; on wheat, fluquinconazole translocation effect, 1345; genotype distribution, S47

Mycotoxin

-aflatoxin: biosynthesis and molecular regulation, S107; competitive exclusion and control, S107; history and programs, S107; host resistance to, S108; management, field based, S107; multi-crop working group, workshop, S108; programs, S107

-trichothecene, tolerance and transgenic approach, S96

Myrobalan latent ringspot virus, purification and characterization, $\mathrm{S} 132$

Myrothecium verrucaria, on kudzu

-bioherbicidal control, S9

-trichothecenes from, $\mathrm{S} 1$

Myrta, A., 1330

Myxococcus spp., pathogenic fungi and biocontrol agents affected by, S72

Nacar, S., 710

Nagata, T., 454

Nagendran, S., S55

Naidoo, G., S27

Naidu, R. A., 214

Nakaho, K., S37

Nakajima, T., S77

Nakatsuka, S., 595

Nakayashiki, H., 1060

Nalim, F. A., S55

Nam, H. G., 1390

Nance, J. L., S128, S128

Naranjo, P., S70

Nault, B., S50

Nault, L., S50

Navas-Cortés, J. A., 1269

Nawar, H. F., S55

Nectria haematococca

-DNA sequences, characterization, S76

-pathogenicity determinants, evolution, S76

Neemann, M., S55

Neemann, N., S22

Nehl, D. B., S67

Nelson, M. R., 1188

Nelson, R. L., S95

Nelson, R. S., S12, S19 
Nematodes

—endoglucanase genes, origin, S86

-fungi parasitic to, use in biocontrol, 498

- teaching exercise, S114

- teaching usefulness, S114

Nesmith, W. C., S126

Nester, E., S93

Nester, S. E., S131

Neuman, M. F., S55

Neurospora crassa, Spitzenkörper, role in growth and morphogenesis, S121

Newcombe, G., 179, S105

Newman, M. A., S55, S84

$\mathrm{Ng}$, J. C. K., S55

Niblack, T. L., S16, S61

Nicholson, P., 666

Nicotiana spp. (see also Tobacco)

-metabolite, fungicidal activity and structural analogs, S71

-proteins, pathogenesis-related, S16

Nishiguchi, M., 944, 1182

Nishimura, S., 595

Nita, M., S56

Nitao, J. K., S56

Noa-Carrazana, J. C., S56

Nordheim, E. V., 657

Norelli, J. L., 72, S56, S64, S65

Noris, E., 629

Norman, D. J., S56

Ntahimpera, N., S56

Ntare, B. R., 214

Nuckles, E. M., S24

Nucleic acid, recovery, molecular diagnostic format, S70

Nunez, J. J., S2

Nutter, Jr., F. W., S21, S22, S59, S60, S101, S103

Oak, wilt, herbicide effect, $\mathrm{S} 11$

Obermeier, C., S57

Obituaries

—-Robert Sidney Cox, 564

-Zahir Eyal, 676

O'Brian, G. R., S56

Obrycki, J., S21

Ocamb, C. M., S78

Ochiai, H., 415

Ockey, S., S121

Odelson, D. A., S66

O'Donnell, K., 891, S96

Odontoglossum ringspot virus, on orchid, molecular beacon approach, 269

Oh, H.-S., 1162

Ohm, H.R., 1043, S42

Ohr, H. D., S119

Oka, Y., 710

Okubara, P., S57

Olatinwo, R. O., S57

Olaya, G., S57, S123

Olivain, C., 1279

Olsen, L., 407

Olsen, M., S10

Olson, B. R., S57

Olson, S. M., S66, S127

Omer, M., S57

O’Neill, N. R., 691, 699, 812, 1126, S77

Onesto, J.-P., 522

Onion

-rot, strain variation and copper tolerance, in Georgia, S130

-white rot, clonal spread and recombination of pathogen, 514

Oosthuizen, M. C., S16

Ophiosphaerella spp., on turfgrass, diagnosis, S97

Ophiostoma spp., wood discoloration, biocontrol strains, S34

Orange, blue mold, postharvest control, sodium compound, S58

Ordoñez, M. E., 197
Orihara, S., S76

Ortiz, J. R., S123

Oruetxebarria, I., 437

Orum, T. V., 1188

Osada, S., S76

Ostrofsky, A., S25

Ostrofsky, W. D., S105

Ostrovsky, M., S111

Ostrow, K. M., 546

Ostry, M. E., S73

Otrosina, W. J., S57, S81, S127

Otani, H., 595, 973

Oudemans, P. V., 390, S15, S82, S103

Overton, S., S69

Ownley, B. H., S58

Oyarzun, P. J., 197

Ozaki, K., 1383

Pacumbaba, Jr., R. O., S35, S58

Pacumbaba, R. P., S58

Padgett, G. B., S58

Page, A., S47

Paguio, O. R., S125

Pair, S. D., S18

Pallás, V., 1330

Palou, L., S58

Palukaitis, P., S45

Palumbo, J., S58

Pan, S. Q., S86

Panaccione, D. G., S44, S71, S96, S133

Panicum mosaic virus

-replicase-associated protein of, S6

-on St. Augustinegrass, genetic diversity, 977

Pantoea spp.

$-P$. agglomerans: biocontrol for barley basal kernel blight, 368; on pear and apple blossoms, environmental factors, 1285; radish bacterial leaf spot control, 327

$-P$. stewartii, on corn: flea beetle monitoring, S22; virulence control, S6

Pantuso, F. S., S26

Panwar, M. S., S84

Papaver somniferum

-Dendryphion penicillatum and Pleospora papaveracea as pathogens, infection process, 699

-Fusarium wilt, biocontrol with Pleospora, 812

- seedborne pathogens, Dendryphion and Pleospora spp. as mycoherbicides, 691

Papaya, virus resistance, socioeconomic effect in Hawaii, S29

Papaya mosaic virus, infectious clones, 35S promoter, S23

Papaya ringspot virus

- coat protein, analysis in transgenic papaya, S27

- coat protein segment, S14

-transgenic, S109

Papiernik, S., S102

Pappu, H. R., 139, S59, S125, S128

Pappu, S. S., S128

Parisi, B. F., S33

Parisi, L., 236

Park, C. H., S40

Park, D. H., S39, S42

Park, J. W., S59, S112

Park, P., 1209

Park, S. Y., S40, S59

Parker, J. E., S40

Parks, R., S118

Parra, G. P., S65

Parra, G. R., 148

Parthenocissus quinquefolia, phytoplasma, new subgroup, S30

Partridge, J. E., S59

Pasteuria penetrans, endoparasite of nematodes, in soil, S117

Pataky, J. K., S25, S53, S59

Pate, M. C., S59

Pathogen —introduced species, risk and epidemiology, S106

-invasion potential, predictive methods, S106

-invasive species, executive order, S106 Patil,

M. A., S59

Patil, M. A., S59

Patocchi, A., S109

Patterson, C. D., S48

Paulus, A. O., S120

Pavek, J. J., S118

Payan, L. A., S123

Payne, G. A., S56, S107

Payton, M., S57

Pea

- defense gene regulation, correlation with high mobility group proteins, $\mathrm{S} 42$

-rhizosphere, microbial ecology and Burkholderia vietnamiensis, $\mathrm{S} 41$

—root rot, PCR assay for detection of pathogen, 1137

Peach

—constriction canker, management strategies, S44

-fruit rot, latent infection in Georgia, S126

-mosaic symptoms, new icosahedral virus, S49

-rust, symptoms, S121

-rusty spot, epidemiology and management, S26

Peachy, E., S36, S61

Peanut

—aflatoxin, harvesting effect, S8

-Groundnut rosette virus, sequence diversity in agents, 214

-leaf spot, chlorothalonil applications, cultivar response, $\mathrm{S} 125$

-soilborne fungi, two communities, S41

Pear, fire blight:

—biocontrol strategies, S101

— control with viral EPS-depolymerase, 1263

-environmental factors, 1285

Pearl millet, fungal and mycotoxin contamination, S129

Pecan, scab, spray advisories, S9

Pecci, M. P. G., S40

Pedersen, W. L., S3, S44, S54

Peever, T. L., 376, 407, 762

Pelargonium spp., bacterial pathogens, amplification competence, $\mathrm{S} 28$

Peltaster fructicola, on apple, temperature and relative humidity effect, 362

Peñaloza-Vázquez, A., S41, S59, S81

Peng, G., S59

Penicillium spp.

$-P$. digitatum: Verticillium lecanii interaction, antibiosis and host defense reactions, 932; Verticillium lecanii, interaction, cover photo, September

$-P$. oxalicum, resistance in tomato induced by, against Fusarium wilt, 260

$-P$. expansum, polygalacturonase, gene cloning and analysis, S87

Penmetsa, R. V., S79

Pennisetum glaucum, striga resistance, gene pool, 1169

Pepper

-Phytophthora capsici, soil core sampling data, S23

- powdery mildew, control, $\mathrm{S} 12$

Peralta, E. L., S124

Percich, J. A., S22

Percifield, R. J., S60

Pereira, R. M., S58

Pereyra, S. A., S60

Perez, E., S92

Perna, N., S92

Pernezny, K., S60

Peronospora spp.

-P. parasitica: on Arabidopsis, resistance signaling, oxygen, S134; on Arabidopsis, 
riboflavin role, 801

-P. tabacina: root interaction, S126; on tobacco, population studies, S75

Perry, C. V., S60

Perry, K. L., 615, 1043, 1068, S55

Pesticide, spray drift deposition, non-target plant implication, S106

Peters, D., 454

Peterson, D. A., S53, S71

Peterson, G. L., 951, S25, S60, S131

Peterson, L. G., S128

Pethybridge, S. J., S60, S61

Petit, E., S27

Pfeiffer, T., S31

Pfender, W. F., S61

Phaeoacremonium spp., mycelial growth and survival, temperature and water effect, S84

Phaeoisariopsis griseola, on bean, molecular markers for subgroup, S49

Phaeosphaeria nodorum, on wheat, neural network classification in field environment, 108

Phakopsora spp., on soybean, detection using PCR, S25

Phanerochaete chrysosporium, wood decay, plasma membrane characterization, S62

Phaseolus vulgaris (see also Bean)

- anthracnose, resistance gene and molecular markers, 758

-white mold, fungicide evaluation, S24

Phatak, S. C., S129

Phialophora gregata

- phenotypic variation, S37

-on soybean: DNA fingerprinting, S52; genotype and molecular marker, 875

Philion, V., 31

Phipps, P. M., S132

Phoma spp.

- P. ligulicola, on pyrethrum, yield and site factors, Australia, S61

-P. macdonaldii: on sunflower, cotyledon petioles, cover photo, August; on sunflower seedlings, mode of penetration, ultrastructure, 915

Phomopsis viticola, on grape, berry and rachis susceptibility, S21

Phytomonas spp., plant parasites, ectophosphatase activities, 1032

Phytophthora spp.: on almond, resistance, S10; on citrus, root weevil complex, S30; diagnostic kits, evaluation, S34; genome, bioinformatics model, S109; recovery in irrigation water, factors, S127; zoospores, encystment factors, $\mathrm{S} 13$; zoospores in irrigation water, S81

-P. capsici:on bell pepper, inoculum dispersal, in soil, 148; on cucurbits, mefenoxam insensitivity, 396; Ridomil Gold sensitivity, in Florida, S122; on squash, disease management strategy, S119; on tomato, age and variety, S65; zoospore encystment, peptide effects, S7

- P. cinnamomi: on Byrsonima crassifolia, in Mexico, S85; composted animal manure effect, potting mixes, 775; on highbush blueberry, resistance, S73; on oak, lesion growth, S76

-P. citrophthora, $P$. parasitica comparison, growth media for, $\mathrm{S} 118$

$-P$. infestans: dimethomorph in a control program, S74; genotypic diversity, population analysis, factors, S31; Ireland population, characterization, S12; on maize, in Maine, S31; mating-regulated cDNAs, S119; mating type, oospores, fungicide formulations, 1201; migrations, world populations, S94; mitochondrial DNA, $19^{\text {th }}$ century herbarium specimens, S65; on potato, field competitive fitness, 220; on potato, host diversity and inoculum pattern, 1307; on potato, oospore production and sprinkler irrigation, 1105; resistance in diploid hybrid of Solanum, S63; self-fertility, genetic factors, 987; from Solanum berthaultii, new R-genes, S68 sporangial survival, solar radiation, 78; on tomato and potato, detection methods, 1112; on tomato and potato, diversity in North Carolina, S82; on tomato and potato, genetic structure, temporal and spatial patterns, 1188; on tomato, resistance genes, S25; on tomato, specialization evolution, S73; on wild potato, novel population in Ecuador, 197; on wild potato, population in Mexico, S31; on wild Solanum spp., isolate characterization, S19; zoospore population, virulence, $\mathrm{S} 1$

-P. nicotianae: $P$. cactorum hybrid, molecular characterization, 867; sporangium production, herbicide effect, S36; on tomato, cabbage amendment and temperature effects, 1089

- P. parasitica: suppression in peat, aluminum, $\mathrm{S} 23$; on vinca, azoxystrobin for control, S32

-P. phaseoli: on lima bean, fungicides, $\mathrm{S} 131$; on lima bean, race profile, $\mathrm{S} 131$; race $\mathrm{E}$, on lima bean, resistance, $\mathrm{S} 132$

$-P$. sojae: isozyme variation, cellulose acetate electrophoresis, S18; nematode relation on soybean, S85; new races in South Dakota, S13; Rps genes, S93; on soybean, pathogenesisrelated proteins, S48; on soybean, resistance, S27; on soybean, tillage effect, S15

Phytoplasma

- on alfalfa, molecular detection, from Oman, 928

- clover phyllody and Cirsium yellows, strain diversity, S39

-host concentration, polymerase chain reaction, 1145

- mulberry dwarf, in leafhopper genital organs and eggs, 909

-Rhus yellows, characterization, S76

Phytotoxins, Colletotrichum dematium, on mulberry leaves, 285

Piccinni, G., S120

Piche, Y., S73

Pickens, J. B., S10

Pierce, M. L., S59

Piercey-Normore, M. D., S133

Pierson III, L. S., S7, S66

Pike, S. M., S61

Pimentel, G., 376

Pine

—disease management, S104

-fusiform rust, molecular approach, S104

-loblolly: fusiform rust, anatomical response, S129; rhizobacteria and ozone response, S22

-longleaf, root disease and insects, S127

—seed health, S104

-southern, fusiform rust, past and prognosis, S98

Pineapple

—mealybug wilt, a virus?, S92

-mealybug wilt, symptom induction, S71

-mealybug wilt-associated virus-2, genome organization, S52

Pinner, M. S., S9

Pinus spp.: diseases in Uganda, S67; root system, histology, S81

$-P$ elliottii, fusiform rust, resistance components, 1005

-P. monticola, rust, population diversity, 1073

$-P$. pungens, ectomycorrhizae, $\mathrm{S} 21$

$-P$. strobus, ectomycorrhizal fungi, reclaimed surface mines, soil properties, S44

Pistachio

-Alternaria spp., molecular characterization, S62

-Fusicoccum, in California, S73

Pitrat, M., 636

Pitz, K. Y., S27

Plantegenest, M., 860

Plaskowitz, J., 699
Plasmodiophora brassica, resting spores, detection in soil, S76

Plasmopara viticola, on grape

-heterothallism, S85

-sporulation factors, S67

Plattner, R. D., S4, S96

Pleospora papaveracea

-biocontrol agent for Fusarium on poppy, 812

-mycoherbicide for poppy diseases, 691

- on Papaver somniferum, cover photo, July

-on poppy, infection and disease, 699

Plum, bacterial spot, in Idaho and Oregon, S120

Plum pox virus

-coat protein, sequence analysis, S132

-Pennsylvania strain, characterization, S46

Plunkett, G., III, S92

Plyler, T. R., S110

Pnini-Cohen, S., 297

Podila, G. K., S5, S75, S88

Podolsky, R., 38

Podosphaera clandestina, on sweet cherry, fungicide management, S31

Poinsettia

-Pythium root rot, biocontrol with composted swine manure, S36

-root rot, biocontrol agents, S30

Polashock, J. J., S27

Polek, M., S72

Polston, J. E., S25, S123, S128

Polymyxa graminis, detection by serology, 537

Poplar

—pathosystems, variation, S105

- Septoria canker, resistance assays, S83

- transgenic hybrids, disease resistance, S12

Populus spp., bronze leaf disease, etiology, S73

$-P$. deltoides, leaf rust, resistance and molecular markers, 1039

Porat, R., S20

Porchas, M., S49

Pordon, M., S93

Porter, P. M., S14

Portetelle, D., S92

Posfai, G., S92

Postharvest pathology

- Botrytis cinerea on carrot, resistance induced in storage, 981

-fruit, biocontrol mechanisms: and methods, 1196; plate insert method, S39

Postma, J., 125

Potato

-Arabidopsis thaumatin-like protein 1, resistance, $\mathrm{S} 117$

-brown rot, bacterial survival in soils, 1358

-cropping systems, soil microbial communities, in Maine, S45

-cyst nematode, infestation foci, 647

-late blight: field competitive fitness, 220; genetics and spatial patterns, 1188; host diversity and inoculum pattern, 1307; inoculum sources, S50; oospore production and sprinkler irrigation, 1105; resistance in transgenic varieties, S20

-scab: actinomycetes in Australia, S44; resistance and tolerance to thaxtomin A, S48; Streptomyces in Korea, S42

-Tobacco rattle virus, detection using polymerase chain reaction assay, 448

-Verticillium wilt, corn and barley rotation, S118

-Verticillium wilt and scab, ammonium lignosulfonate for control, S73

_-virus resistance, $\mathrm{S} 118$

Potato leafroll virus

-aphid acquisition and cell transport, P5 readthrough protein, 1153

- potato spindle tuber viroid mixture, interaction, S75

- systemic infection, movement protein requirement, S45 
Potato mop top virus, detection, polymerase chain reaction assay, 448

Potato virus $V$, genomes from Europe, molecular characterization, 437

Potato virus $X$

- antimicrobial expression cassette, S88

- in Ipomoea nil, Sweet potato feathery mottle virus role in spread, 944

Poupet, A., 522

Powell, C. A., S61

Powell, W. A., S12, S46, S105

Powelson, M. L., S36, S61

Powers, Jr., H. R., S98

Pozdnyakova, L., S103

Prairie, green leaf biomass and leaf litter, in Iowa, S60

Prasad, S., S61

Pratt, R. G., S61

Preston, G. M., S59

Pretorius, Z. A., 1026

Prins, M., 183, 454

Proctor, R. H., S96

Prom, L. K., 1079

Prune, French, bacterial canker, rootstock effect, S69

Prune dwarf virus, detection with molecular hybridization and polymerase chain reaction, 1330

Prunus necrotic ringspot virus

—in Australian hop gardens, S60

- detection with molecular hybridization and polymerase chain reaction, 1330

- on rose, detection methods, 522

Prusky, D., 553, 1256

Pryor, B. M., S62

Pseudomonas spp., biocontrol activity, S19

$-P$. aeruginosa, ryegrass blast controlled by, factors, $\mathrm{S} 80$

$-P$. aureofaciens: biofungicide characterization, phenazine production, S66; phenazine biosynthesis, regulation, S7; on turfgrass, field evaluation, S33

-P. putida: biocontrol using irrigation water, S74; Rhizoctonia root rot of apple controlled by, carbon effect, S31

$-P$. syringae: alginate production, plasmid mutagenesis, S23; amended names, letter to editor, 208; on Arabidopsis, genetic analysis, S47; on Arabidopsis, resistance signaling, oxygen, S134; on Arabidopsis, riboflavin role, 801; biocontrol agent for barley basal kernel blight, 368; on cantaloupe, host range and genetic diversity, in France, 636; coronatine biosynthesis, regulation, $\mathrm{S} 81$; coronatine, histidine protein kinase, S63; coronatineproducing strains, detection, S88; effector loci, analysis, S64; genomic approach, S108; host range, Hrp type III protein secretion, S24; hrp/hrc gene clusters, analysis, S63; phytotoxins, genetic map, S70; on rappini, delayed replanting factor in California, $\mathrm{S} 15$; regulatory genes, syringomycin production, S48; resistance gene functions, genomic dissection, S110; tabtoxin-producing strains, detection, $\mathrm{S} 48$; on tomato, alginate biosynthesis, Hrp system and copper, S41; on tomato, effector locus, S4; on tomato, incidence in North Carolina, S47; on tomato, protein secretion system and coronatine biosynthesis, S59; on tomato, $\mathrm{R}$ gene pathway, $\mathrm{S} 86$; on tomato, specific determinants, S76

-P. tolaasii, on mushroom, PCR detection, S13

Puccinia spp.

- . graminis: on grasses, modeling latent period, S61; on wheat, avirulence genes, DNA markers, 819

-P. hordei, on barley, resistance genes, 1131

- $P$. jaceae: on safflower, teliospore as inoculum, S10; yellow starthistle controlled by, genetic variation, $\mathrm{S} 87$

$-P$. recondita, on wheat, virulence diversity, populations in Israel, 601

- P. sorghi, on sweet corn, Rp genes, S59

$-P$. striiformis, on wheat, plant density and cultivar effect, 1313

-P. substriata, on pearl millet, multiline strategy for management, $\mathrm{S} 84$

-P. triticina, on wheat, virulence and molecular polymorphism in international collections, 427

Puckhaber, L. S., 248

Puhler, A., S92

Punja, Z. K., S120

Purcifull, D. E., S126

Purvis, A., S130

Pusey, P. L., 1352

Putievsky, E., 710

Pyrenophora tritici-repentis

- ascospore production, conditions, S25

-races, host selective toxins, S2

-on wheat, neural network classification in field environment, 108

Pyricularia grisea

-on bentgrass and bluegrass, pathogenicity, S78

- genetic and molecular markers, characterization in USA, 1396

-on rice: molecular and cytological studies, S55; variability in Bhutan, 621

-on ryegrass and tall fescue, management factors, S79

Pyrowolakis, A., S62, S120

Pyrus pylifolia, scab, infection behavior, 1209

Pythium spp., Phytophthora compared to, protein gene sequence, $\mathrm{S} 87$

$-P$. aphanidermatum: on cucumber, microflora effect on disease, 125; on turfgrass, fungicide application strategies, S59

$-P$. arrhenomanes, on sweet corn, herbicide effect, S36

-P. ultimum: on cucumber seedlings, seed treatment, cover photo, January; disease progression and biocontrol, rhizobox system, 1049

Qi, M., S86

Qi, W. H., S62

Qin, X. T., S13, S62

Qiu, D., S62

Qiu, W. P., S62, S112

Quiñones, M., S124

Quiroga-Madrigal, R., S123, S124

Raccah, B., 1056

Rademaker, J., 677

Radish

-bacterial leaf spot, biocontrol, 327

-bacterial spot, compost-induced resistance, other organisms, S43

Rahe, J. E., S99

Raid, R. N., S60

Raina, R., S54

Ralph, J., S74

Ralstonia solanacearum

— genome sequencing project, S93

-mutants, non-motile, S37

-on potato, biovar 2 survival in soil, 1358

- species-specific monoclonal antibodies, S3

-on vegetables, detection by PCR fingerprinting, S56

Ramamurthy, L., S47

Ramanjulu, V., S62

Ramirez, P., S33

Ramon, M. P., 197

Ramonell, K. M., S63

Ramos, A. R., S63

Ramsey, N. E., S33, S63

Randall-Schadel, B. L., S63

Rangaswamy, V., S63

Raposo, R., 1246
Rapp, R. A., S24

Rascoe, J., S63

Rasmussen, J. B., S25

Rathjen, J. P., S110

Rauyaree, P., S64

Ravid, U., 710

Rayside, P. A., S127

Reavy, B., 1153

Rech, E. L., S23

Red clover necrotic mosaic virus, capsid protein, trans-activation, RNA-2 sequences, S111

Reddy, A. S. (India), 537

Reddy, A. S. N. (Colorado), S117

Reddy, D. V. R., 537

Reddy, M. V. B., S56

Redinbaugh, M. G., S64

Reedy, R., S58

Reese, C. D., S14

Rehm, A. H., S64

Reich, L., S56

Reichard, S. H., S106

Reid, C., S11

Reid, J., S50

Reigel, D. G., S85

Reinach, F. C., S93

Reissinger, A., S64

Reitz, M., S72

Rekah, Y., 1322

Remick, M. D., S64

Remington, D., S95

Remphrey, W. R., S36

Ren, R., S87

Renard, M., 961

Resende, L. V., S10

Resende, R., S5

Resendiz, R., S56

Resistance

-apple to scab, Trichoderma endochitinase effect, 72

-barley to Fusarium head blight, trait loci mapping, 1079

-barley to leaf rust, resistance genes, 1131

- barley to scald, histopathology, 94

- corn to Aspergillus ear rot, 292

- corn to gray leaf spot, quantitative trait loci, 1018

—plants to fungi, plasma membrane-cell wall adhesion, S52

-riboflavin, transduction pathway, 801

-slash pine to fusiform rust, components, 1005

- tomato to Fusarium oxysporum, histology, 260

- transgenic disease, durability, S101

Restrepo, S., 683, S64

Retig, B., 834

Reviewers, acknowledgment of, 4

Reynoird, J.-P., S56, S65

Rezende, J. A. M., S53

Rhizobium etli, resistance to potato cyst nematode induced by, S72

Rhizoctonia spp.: on grasses, disease detection, S97; on strawberry, in California, 345; on turf, azoxystrobin sensitivity, S123; on turfgrass, diagnostic features, S96

- R. solani: on cotton, seed treatment with Trichoderma, terpenoid synthesis, 248; damping-off of bedding plants, binucleate Rhizoctonia for, S126; on impatiens, binucleate Rhizoctonia effect, S36; on potato, seedpiece treatments, S70; in soil, control by organic amendments and tarping, 253; on soybean, anastomosis group distribution, S34; on soybean, chloride effect, S3; storage, evaluation method, S126

Rhizopycnis vagum, on melon, root pathogenicity, S123

Rhizosphere

-bioassay screening method, systemic resistance, 327

—microbial populations, consequences, 1181 
Rhynchosporium secalis, on barley

- detection on seed, S45

- genetic structure of field populations, 901

-histopathology, 94

Riault, G., 860

Rice

-bacterial blight: genetic diversity of Sri Lanka strains, 415; molecular changes in resistance gene, $\mathrm{S} 4$

-blast: genetic variability and population structure, in Korea, S59; infection and host cell death, jasmonic acid relation, S45; manganese effect, S37; pathogenic variability in Bhutan, 621 ; resistance gene and avirulence gene products, S110

- disease resistance pathways, genetic dissection, $\mathrm{S} 110$

-false smut, mycotoxins, S1

-fungal diseases, tolerance and puroindoline genes, S43

- grain rot and seedling blight, seed disinfectants and bacteria, S37

-redox balance, salicylic acid role, S86

-retrotransposon Osr1, identification, S40

-Rhizoctonia solani, systemic resistance and chitinolytic bacteria, S42

Richardson, E. A., 843

Riches, E., S65

Ridout, M. S., 568, 738

Riegel, C., S128, S128

Riggs, R. D., S77

Riley, D. G., S59

Riley, T., S29

Riquelme, M., S121

Ristaino, J. B., 148, 1201, S65, S82

Ritchie, D. F., S43, S65, S66

Rivas-Davila, M. E., S32, S65

Rivera, C., 1098

Roane, C. W., S133

Robert, C., S93

Roberto, F. F., S104

Roberts, D. P., S4, S53, S65, S133

Roberts, P. D., S65, S74, S122, S124

Roberts, R. E., S70

Robertson, D. G., S124

Robertson, N. L., S66

Robin, C., 730

Robinia pseudoacacia, witches' broom, phytoplasma related to grapevine yellows, S18

Robison, D. M., S44

Rodionova, N. P., S111

Rodrigues, C. O., 1032

Rodríguez-Cerezo, E., 1098

Rodríguez-Kábana, R., S123, S124

Roebroeck, E. J. A., 891

Rogers, M. B., S66

Rojas, C. M., S66

Rojas, M. R., S39

Rolland, D., 31

Rolshausen, P. E., S66

Romaine, C. P., S16, S80, S81

Romaine, P., S54

Romeiro, A., 1032

Romero, A. M., S43, S66

Rominger, R., S106

Rong, R., S66

Rong, X., S66

Roossinck, M. J., 977

Rosa damascena, antibacterial effect of oil from, S5

Rose

- downy mildew, latent infection, S2

- powdery mildew, compost and Trichoderma effect, control factors, S69

Rose, D., S92

Rosner, A., 340

Ross, K., S16

Rosskopf, E. N., S66

Rosso, M. N., S86
Rotenberg, D., S67

Rothrock, C. S., S67

Rott, M. (Germany), 1145

Rott, M. E. (BBA), S67

Rott, P., S18

Rotylenchulus reniformis, on pineapple, damage threshold, S72

Roustaee, A., 915

Roux, J., S5, S67

Rowe, D. E., S50

Rowe, R., S57

Rowhani, A., S28, S38, S88

Royse, D. J., S16

Rubio, L., S67, S72, S91

Rudolph, K., 208

Ruer, D., 961

Rufty, R. B., 139

Ruhl, G. E., S113, S114

Ruíz-Castro, B. S., S56

Rumbolz, J., S67

Rundell, P. A., S61

Rupe, J. C., S28, S68

Rush, C. M., S120

Russell, P. E., 1345

Ryals, J. A., S113

Ryan, D., S69

Ryan, J. L., 812

Ryder, E. J., S7

Ryegrass, gray leaf spot

-fungicide, herbicide, and growth regulator effect, S78

- temperature and leaf wetness effect, S71

Saad, A. T., S68

Saade, M., 1330

Sabanadzovic, S., S88

Saeed, I. A. M., S67

Saftner, R. A., S46

Saiki, T., 909

Sakamoto, J. M., S68, S121

Salamati, S., 901

Salanoubat, M., S93

Salati, R. S., S39

Saleh, A. A., S68

Salomon, R., 505, S70

Sammons, B., 1043

Sams, C. E., 769, S46

Samson, R., 636

Sanchez, G. M., S68

Sanchez-Navarro, J. A., 1330

Sanders, H., S130

Sands, D. C., 368

Sanogo, S., 57

Saprolegniaceae, virulence and physiological characteristics, S118

Saremi, H., 103

Sasaya, T., S68, S77

Sato, M., 909

Sato, T., S68, S77

Satoh, H., 311

Satoh, N., 311

Satyanarayana, T., S2, S30, S69

Saunders, F. H., Jr., 19

Saurin, W., S93

Sauter, H., S3

Savy, C., 915

Sawyer, T. L., 1285

Saygili, H., S79

Sayler, R. J., S69

Scagliusi, S. M., 120

Scala, A., S69

Schaad, N. W., 208, 951, S54, S69

Schardl, C. L., S96, S126

Scheets, K., S69

Schelberger, K., S3

Scherm, H., 57, S17, S125, S126

Scheuerell, S. J., S69

Schiex, T., S93

Schiff, N. M., S84
Schilder, A. M. C., S11, S57

Schiller, C. T., S2

Schisler, D. A., S42, S69

Schizaphis graminum, luteoviruses transmitted by, variability, S30

Schlueter, K. O., S57

Schmidt, F. J., S7

Schmidt, R. A., 1005

Schmidt, W. F., S56

Schmitt, D. P., S72

Schmitt, M., 1239

Schnabel, E. L., S100

Schnabel, G., S70

Schneider, A. T., S118

Schneider, S., S83

Schnider-Keel, U., S20

Schoedel, B. A., S70

Schoelz, J. E., S16, S41, S111

Scholthof, H. B., S53, S59, S62, S112

Scholthof, K.-B. G., 977, S6, S53, S113

Scholz-Schroeder, B. K., S48, S70

Schomaker, C. H., 647

Schots, A., 183

Schulze, D. G., S37, S77

Schumann, G. L., S114, S115

Schupp, P., S85

Schuster, G., S70

Schuster, R.-P., S62

Schuster, S., 297

Schwartz, H. F., S117

Sciumbato, G. L., S1

Sclerotinia spp.

$-S$. minor: genetic variation, detection method,

$\mathrm{S} 14$; on lettuce, broccoli rotation effect, sclerotia, S34; on peanut, isolate aggressiveness, S72

-S. sclerotiorum: isolate aggressiveness and mycelial compatibility, S44; on soybean, factors in North-Central USA, 1375; on tobacco, ascospore distribution in greenhouses, S34

Sclerotium spp., mycelial compatibility groups, genetic diversity, S120

$-S$. cepivorum, on onion, clonal spread and recombination, 514

-S. rolfsii: mycelial compatibility groups, genetic variation, South Africa, 1026; soil treatments and solarization, 751

Scott, D. (Georgia), S20, S34, S70

Scott, D. B. (New Zealand), S96

Scott, J. W., S93

Scupham, A. J., S70

Sears, J. L., S57

Secor, G. A., S1

Sedegui, M., S131

Seem, R. C., S24, S26, S35

Seemüller, E., 1145

Seguin, M., S93

Seifers, D. L., 505, S70

Seifried, S. E., S27

Seijo, T. E., S123, S128

Seiridium spp., on cypress, molecular sequence data, S5

Sellers, P., S116

Semenov, A. M., 1181

Semer, C. R., S126

Septoria spp.

- S. musiva, on poplar, resistance, gene encoding antimicrobial peptides, S46

- S. passerinii, on barley, relation to Mycosphaerella graminicola on wheat, S29

$-S$. tritici: on wheat, detection, immunoassay, S60; on wheat, interaction using $\beta$-glucuronidase, 297

Seronoa repens, fruit loss, S124

Serfontein, J. J., S69

Serlemitsos, K. A., S71

Serratia plymuthica, biocontrol agent for Pythium on cucumber, 45 
Sesumi, Y., 1060

Sether, D. M., S52, S71, S92

Sexstone, A. J., S133

Sforza, P. M., S71, S75, S133, S134

Shababi, M., S41, S111

Shabi, E., 608

Shahjahan, A. K. M., S37

Shakya, D. D., S71

Shan, L.-B., S76

Shane, M. S., S68

Shaner, G., S4

Shani, Z., S28

Shao, Y., S92

Shapiro, A. D., S134

Sharer, C., 1196

Sharon, A., 297

Sharp, L. P., S53, S71

Shaw, D. S., 1105, S19

Shaw, L. N., S128

Shaw, M. W., 333, 1345

She, Y.-M., 505

Sheets, N. L., S44, S71

Shelton, J. E., S71

Shelton, K. L., S128

Sherald, J. L., S106

Sherwood, J. E., S43

Sherwood, J. L., 1233, S125

Sherwood, T., S128

Sheta, H. M., S72

Shetty, K. G., 305, S72

Shew, B. B., S63, S72

Shier, W. T., S1

Shih, B. Y., S88

Shimono, M., 944

Shiotani, H., 1383

Shirata, A., 285

Shishkoff, N., S133

Shoemaker, P. B., S25, S47, S82, S119

Shoseyov, O., S28

Shtienberg, D., 834, 1181, 1322

Signal amplification system, detection of biotinylated molecules, evaluation, S20

Signoret, P., 505

Sikora, R. A., S19, S62, S64, S72, S99, S120

Silva, J., S78

Silva-Rosales, L., S24, S56

Sim, J., S72

Sim, S. T., S28

Simini, M., S107

Simko, I., S68

Simpson, A. J. G., S93

Sims, A. L., S60

Sims, J. J., S21, S119

Sinclair, W. A., S30

Singleton, L., S57

Sinorhizobium meliloti, genome analysis, S92

Sipes, B. S., S72

Sirvent, T. M., S72

Sit, T. L., S32, S111

Skaria, M., S35, S40, S73, S80

Skulachev, M. V., S111

Slack, S. A., S12

Smalley, E. B., S98

Smart, C. D., 197, 987. S68, S73, S94

Smilanick, J. L., S58

Smith, B. J., S73, S83, S129

Smith, D. (New York), S30

Smith, D. R. (Wisconsin), S73

Smith, G. P., S7

Smith, H. G., 460

Smith, J. A. (Nebraska), S34

Smith, J. A. (Minnesota), S73

Smith, O. P., S132

Smith, R. F., S7

Smith, S., S108

Smith, T. H., S127

Smither-Kopperl, M. L., S73, S79

Snape, J., S65

Snider, C. S., 354
Snow mold fungi, ice nucleation and pathogenesis, 354

Snook, M. E., S32

Snyder, C. L., S25

Snyder, K. E., 951, S28

Sobral, B. W. S., S109

Soderhall, K., S118

Sohn, H. B., S42

Soika, M. D., S78

Soil amendments, paper-mill sludge, foliar disease suppression, S79

Soil solarization

-impatiens soilborne pathogens, Florida, S127

- soilborne pathogen control, 751

Soil suppression

- cyst and root-knot nematodes, evaluation, S62

- Heterodera schachtii on Swiss chard, transfer, 401

Soilborne disease control, chitin from crabshells, ammonium and nitrate concentration, S73

Sokolski, S., S73

Solanum tetrapetalum, Phytophthora sp., novel population in Ecuador, 197

Solfrizzo, M., S40

Solis-Gracia, N., S40

Soltani, N., S73

Somda, I., 961

Somerville, S., S63

Sonoda, S., 944, 1182

Sorensen, L. H., S118

Soto, M. J., S74

Soto-Estrada, A., S121

Soule, J. D., S70

Southwick, S. M., S69

Soybean

-brown stem rot, molecular markers, 875

-cropping sequence effect, S14

- cyst nematode: genes, S108; secretory protein genes, S82

- dwarf-like virus, in Virginia, S132

- foliar sprays, yield and seed quality effect, S51

-Fusarium solani, cell response in roots, S28

- germ plasm and genomics, challenges, S95

- glyphosate-tolerant, herbicide effect, 57

-lactofen application, disease control, S6

-Phomopsis seed infection, resistance, S38

-reniform nematode on, Aldicarb effect, S51

- Rhizoctonia solani, inoculation method, S78

-Sclerotinia stem rot: factors in North-Central USA, 1375; systemic resistance, S86

— seed fungicides, application effect, S26

—seed quality: fungicide effect, S51; histological quality evaluation, S26

-stem canker, planting date effect, S68

- sudden death syndrome: molecular differentiation of Fusarium spp., rDNA sequence, 491; partial resistance, grafting, S54

Soybean dwarf virus, dwarfing strain, RNA genome, cloning and sequence analysis, S132

Soybean mosaic virus

- hypersensitivity and resistance, S32

-model disease-progress-curve, infection time, yield loss, 788

-resistance, non-necrotic mechanism, S23

Soybean severe stunt virus

- cDNA clone characterization, S131

- gene expression, S6

Spaine, P. C., S74

Spetz, C., 437

Sphaceloma manihoticola, on cassava, Brazilian isolates, $\mathrm{S} 2$

Sphaeropsis sapinea

-on Austrian and Scots pines, latent infection, S24

-morphotype characterization, S18

- on red pine, detection medium, S7

Sphaerotheca spp.

-S. fuliginea, on cucurbits, azoxystrobin resistance, monitoring study, S57
-S. macularis, on hop, management, S78

$-S$. pannosa, on rose, genetic diversity in Colombia, S3

-S. xanthii, on cucurbit, new combination, S133

Spiegel, Y., 710

Spinach

-downy mildew, race 6 resistance, S16

-Fusarium wilt, resistance screening, S44

-white rust: epidemiology and management,

S128; surfactants for control, S37

Spiroplasma citri

—serological and molecular markers, S6

- surface protein P89, cell adhesion to vector, 716

Squash

- lignin-like material from fruit, chemical composition, S74

- virus diseases, aphid transmission and resistance, in Florida, S126

Srivastava, M. P., S61

Stack, J. P., S59

Stagonospora nodorum

-hydrolytic enzyme, cell wall components, S17

- mating type-specific primers, S6

-on wheat: detached-leaf assay, S42; detection, immunoassay, S60

Stall, R. E., S74

Standing, K. G., 505

Stange, R. R., S74

Stanghellini, M. E., 243, S82, S119

Staniulis, J., S39

Stanosz, G. R., S7, S73, S83, S105

Stanosz, J. C., S83

Statistical measures, quadrat-based, spatial aspects of disease data, letter to editor, 568

Statistics, spatial, spore dispersal, quadrat size and shape, 738

Stavisky, J., S26

Stebbins, T. C., S55, S84

Steddom, K., S74

Steffenson, B. J., 1079, 1131

Stein, J. M., S74

Steinberg, C., 1279

Stenger, D. C., 546, S25, S33

Stenotaphrus secundatum, Panicum mosaic virus, genetic diversity, 977

Stenotrophomonas maltophilia

-beta-glucanases from, characterization, S58

-biological control activity, extracellular enzymes, S58

-on tall fescue, chitinase role in biocontrol, 384

Stephenson, M. G., S125

Stevens, M., 460

Stevenson, K. L., S11

Stewart, E. L., S31

Stienstra, W. C., S14

Stierl, R., S74

Stilbothamnium togoense, phytotoxic metabolite from, S50

Stipanovic, R. D., 248

Stipes, R. J., S132

St. Martin, S., S93

Stockwell, V. O., 1285, S101

Stone, A. G., S79

Stone, A. L., S132

Stone, R., S115

Storer, A. J., S8

Stowell, L. J., S97

Strausbaugh, C. A., S24

Strawberry

- Alternaria alternata, infection-inhibiting factor, 595

-anthracnose: latent infection, detection by freezing, S53; zosteric acid efficacy, S129

-Botrytis cinerea, fruit rot, suppression by Messenger, S15; modeling infection, P0838

-Botrytis fruit rot: fungicides for, S46, harvest factors, S7

—endophytic bacteria, S16 
-foliar diseases, analysis, 157

- fruit rot, fungicides, S120

-leaf blight, severity assessment, S56

-leaf spot, temperature and leaf wetness effect, 1120

-methyl iodide and chloropicrin effect on yield, S21

-microbial compost system, methyl bromide comparison, S30

- powdery mildew, temperature and water vapor pressure, $\mathrm{S} 120$

-Rhizoctonia spp., California, 345

-root colonization, transplant and soil disinfestation treatment, S66

—root pathogens, biocontrol, S102

Street, C. A., S55

Streptomyces spp., pathogenicity evolution, pathogenicity island transfer, S47

$-S$. scabies, on potato: marked strains, S41; necrosis and nec1, S66; thaxtomin A, monoclonal antibody specific, S39

Striga hermonthica, on pearl millet, resistance, 1169

Stromberg, E. L., S75, S133, S134

Stromberg, V. K., S75, S134

Su, H., 67

Subbarao, K. V., 67, 305, 827, 995, S7, S34, S72, S85

Subrahmanyam, P., 214

Subramanya, S. R., S74

Sudarshana, M. R., 1224, S35, S39, S75, S87

Sugar beet

- Cercospora leaf spot, autecology and mode of action, S101

- chitinase production, defense response, S55

- crown and root rot, resistant varieties, S33

- performance trial, multi-state, S34

-Pythium seedling disease, survey in Michigan, S39

—virus yellows, synergism and host effects, S92

-yellowing diseases, three virus causes, 460

Sugar, D., 1285

Sugarcane, yellow leaf syndrome:

- diagnostic method for detection, S43

-luteovirus association, 120

- symptoms, cover photo, February

Sugarcane yellow leaf luteovirus, transmission and serology, 120

Sujkowski, L. S., 148

Sukno, S., S75

Sullivan, B. T., S127

Sullivan, M. J., S128

Sullivan, R., S58

Sulzinski, M. A., S28

Sumner, D. R., S129

Sun, J., S39

Sun, L. J., S120

Sun, Q., S108

Sun, X., S29

Sundaram, S., S75

Sundin, G. W., S38

Sunflower, black stem, penetration mode, ultrastructure, 915

Sung, S. S., S127

Suppressive soil, bacterial communities, identification using DNA micro array, S8

Sutton, T. B., 362, S21, S29

Sutula, C. L., S103

Swafford, M., S3

Swanson, S., S75

Sweet potato chlorotic stunt virus, detection, S72

Sweet potato feathery mottle virus

-Potato virus X affected by, in Ipomoea nil, 944

-resistance, 1182

- serotypes in Uganda, cultivar interaction, 1250

Swings, J., 677

Swiss chard, beet cyst nematode, transfer to conducive soil, 401

Syller, J., S75
Szyndel, M. S., S75

Szabo, L. J., 819

Tabor, G. M., 1039

Tainter, F. H., S21, S66, S76, S85, S98

Tak, H., S1

Takahashi, T., 311

Takayama, T., S76

Talbot, M. M., S45

Tanaka, A., 762

Tanaka, M., S76

Tande, C., S13

Tang, X. Y., S47, S76, S86

Tans-Kersten, J., S37

Tanzer, M., S47

Tapesia yallundae, on wheat

— genetic structure, S20

-in Pacific Northwest, S118

Tarchini, R., S110

Taylor, A., S75

Teaching

-biological sciences, plant pathogens as tools,

S114

-Gram stain, S115

-plant pathology and weed science, 3-D animations and virtual reality, S71

- powdery mildew fungi, classification, S114

- water molds, S114

Tedford, E., S123

Temporini, E. D., S76

Tenuta, M., S16

Termorshuizen, A. J., 253, S29

Terrada, E., 1337

Teviotdale, B. L., S29

Tewari, J. P., 94, S45

Thara, V. K., S76

Thebault, P., S93

Thielaviopsis basicola

- on cotton, exudate effect on reproduction, S67

-on pansy, penetration and infection ultrastructure, 843

Thies, J. A., S76

Thirumala Devi, K., 537

Thomas, C. (Georgia), S20, S34

Thomas, C. E. (Sourth Carolina), S40

Thomas, G. G., S134

Thomas, J. E., 921, 1295

Thomas, P. L., 179

Thompson, C. M., S126

Thompson, D. (New Jersey), S77

Thompson, D. F. (California), S2

Thompson, I. A., S77

Thomson, S. V., S33, S44, S121

Thon, M. R., S77

Thornsberry, J., S95

Thinlay, 621

Thryptomene calycina, Phytophthora cinnamomi on, suppression by composted manure, 775

Tian, H., S77

Tian, T., S91

Tilahun, D. A., S77

Tilletia spp., mating pheromones, inhibition mechanism, S43

-T. controversa: races, five new resistance genes, S28; T. bromi population compared to, variation, 376

-T. indica: escape-proof containers for field studies, S131; T. walkeri differentiated from, PCR identification method, 951

- T. walkeri, teliospore, survival, S3

Timmer, L. W., 407, 762, S125

Tingey, S., S93

Tisserat, N. A., S97

Tobacco (see also Nicotiana spp.)

-Actigard effect on growth, S39

- cell suspension, Ralstonia solanacearum, nitric oxide, S15

-cyst- and root-knot nematodes, endoglucanase gene expression, $\mathrm{S} 28$
_ Globodera on, soil core sampling data, S23

-hypersensitivity, S11

-hypersensitivity, ADP-ribosylation factor, S14

-root-knot, cyst nematode, and broomrape, genetic engineering strategies, resistance, S51

-Tomato spotted wilt virus, resistance, in field, 139

Tobacco mosaic virus

-on Arabidopsis thaliana, seed transmission, 1233

- elicitor and protection functions, S112

- gene expression and translation, S111

- protein $126 \mathrm{kDa}$, region identification, S12

- salicylic acid-inducible gene and $N$ genemediated resistance, $\mathrm{S} 46$

- systemic resistance, riboflavin role, 801

Tobacco rattle virus, detection, polymerase chain reaction assay, 448

Todd, J. W., S83, S99, S128

Tolin, S. A., S23, S50, S132, S133

Tomato

-bacterial canker, bactericides, 38

-bacterial disease, copper for control, S132

-bacterial pathogens, breeding for races, S93

-bacterial spot, Bacillus subtilis biocontrol agent, S36

-blackmold: environemental conditions, S121; epidemiology in California, S68

-damping-off, biocontrol with Beauveria bassiana, $\mathrm{S} 58$

-Fusarium crown and root rot, airborne conidia, 1322

-Fusarium wilt: Pseudomonas fluorescens for control, factors, S20; resistance induced by Penicillium oxalicum, histology, 260

-late blight, genetic diversity and patterns, 1188

- phyllosphere, rhizosphere, and endosphere, benzothiadiazole effect, S55

— pith necrosis, factors, S79

-powdery mildew, control, S12

- pseudomonad and benzothiadiazole effect, S22

-Pto kinase, perception and transduction, S110

-Rhizoctonia root rot, Bacillus for biocontrol, S6

-root-knot nematode: Abamectin efficacy, S123; essential oils for control, 710

-soilborne pathogens, oils for management, S127

-Verticillium wilt, cropping practice effect, in Ontario, 1011

Tomato bushy stunt virus

-posttranscriptional gene silencing, p19 protein, S62

— protein expression strategies, S111

-resistance genes, transgenic plants, S112

-RNA accumulation, S59

Tomato leaf crumple virus, Chino del tomate virus relation, 546

Tomato mottle virus, on tobacco, BC1 gene for transformation, $\mathrm{S} 25$

Tomato spotted wilt virus

- antibodies and virus-binding proteins, S84

-management options, S59

-on peanut: regression approach, S83; risk assessment, S114; variation in Georgia and Florida, S128

-phage display, diagnosis in ELISA, 183

-thrips transmission, 454

-in tobacco, plant activator and insecticide effect, S125

- transgenic resistance, 139

Tomato yellow leaf curl virus

- cultivar tolerance, in Dominican Republic, S123

- diagnosis, S9

-dissemination factors, S128

-movement proteins, subcellular localization, S39

—weed hosts in Florida, S18 
Tomioka, K., S68, S77

Tomita, R., 1060

Tooley, P. W., 951, 1112, 1126, S34, S77

Torres, V., S124

Torres-Jerez, I., S122

Tosa, Y., 1060

Tospovirus, antiviral strategy, cap-snatching, S22

Trail, F., S86, S96

Traunfeld, H. J., S106

Travis, J. W., S31, S35

Trent, M., S17

Trevathan, L. E., S122

Trick, H., S108

Trichoderma spp.

- T. hamatum, radish bacterial leaf spot control, 327

-T. harzianum: antifungal enzymes synthesis, nitrogen effect, S20; endochitinase from, apple scab resistance, 72; gene encoding beta-1,3 glucosidase, $\mathrm{S} 20$

$-T$. virens, elicitor from, defense response, $\mathrm{S} 34$

Trifolitoxin, mutagenesis, site-directed, S70

Trifolium alexandrinum, Bean yellow mosaic virus on, waste management system, S50

Trigiano, R. N., 769

Trinidad-Correa, R., 1188

Triplett, E. W., S34, S35, S41, S70

Truol, G., S40

Tscherne, D. M., S24

Tsuge, T., 762

Tsujimoto, M., S77

Tsuyumu, S., 1383

Tubajika, K. M., S17

Turechek, W. W., 157, S78

Turfgrass, bacterial antagonists, mushroom substrate, $\mathrm{S} 81$

Turgeon, B. G., S6, S109

Turina, M., S6

Turkensteen, L., S31

Turkington, T. K., 94, S45

Turner, J., S53

Turnip yellow mosaic virus, on Arabidopsis thaliana, seed transmission, 1233

Turpin, R., S20, S34, S70

Tuttle, N. T., S78

Tweddell, R. J., S51

Tworkoski, T. J., 1196, S39

Tylka, G. L., S85

Tzeng, D. D. S., S13, S14, S15, S36

Tzeng, H. L. C., S15

Uchida, J. Y., S78

Uchida, R. S., S78

Uddin, W., S71, S78, S80, S81

Ueng, P. P., S17

Ullah, Z., S78

Ullman, D. E., S72, S84

Umemoto, S., 1209

Umezawa, M., 311

Uncinula necator

-azoxystrobin and myclobutanil sensitivity, S85

-on grape: berry infection, S24; control, S45; rot and wine quality effect, S26

Undersander, D. J., 657

Upchurch, R. G., S79

Uphoff, M. D., S86

Urban plant pathology

—diagnosis, prevention, and control, S106

- monument trees, S106

— salt and air pollution, tree symptoms, S107

- trees and sites, S106

Ureña-Padilla, A., S79

Uribe, P., S79

Urrutia, T., 1246

Urs, R. R., S65, S122, S124

Usall, J., S58

Ustilago spp.

$-U$. hordei, mating pheromones, inhibition mechanism, S43

$-U$. maydis: dimorphic phase, differential genes, S28; dimorphism and pathogenicity, protein phosphatase $2 \mathrm{~B}, \mathrm{~S} 126$

$-U$. nuda, on barley, carboxin resistance, 179

Ustun, N., S79

Vaccinium corymbosum, Alternaria fruit rot, epidemiology in Pacific Northwest, S117

Vaiciunas, S. S., S79

Vaillancourt, L. J., S24, S77

Valent, B., S110

Valiunas, D., S39

Valkonen, J. P. T., 437, 1250

Vallad, G. E., S79

Vallejos, C. E., S110

Valverde, R. A., 723, S72

Van Alfen, N. K., S124

Van Arsdel, E. P., S76, S85

van Bekkum, P., 1358

van Bruggen, A. H. C., 67, 827, 1181, S86

Vance, V. B., S127

Vandemark, G. J., 1137

van den Bosch, F., 576, S106

van der Wolf, J. M., 1358

van Elsas, J. D., 125, 1358

van Emden, H. F., S77

VanEtten, H. D., S76

VanHouten, W., S110

van Overbeek, L. S., 1358

van Twisk, C., 183

Vasanthakumar, A., S80

Vaucheret, H., S127

Vauterin, L., 677

Vela, L. B., S80

Velasco, J. A., 197

Velasquez, L., S80

Vélez, C. M., 683, S64

Venter, M., S80

Venturia spp.

-V. inaequalis: on apple, biocontrol, 31; on apple, potato gst 1 promoter, S65; drug efflux pumps, characterization, S70; on Malus sp., races 6 and 7, host-pathogen genetics, 236; oxidase gene, characterization, S70

-V. nashicola, on Asian pear: cover photo; infection behavior, 1209

Vera, C. Cruz, S4

Verdier, V., 683, S64

Verticillium spp.

-V. dahliae: on cauliflower, broccoli-mediated reduction, mechanism, 305; on cauliflower, irrigation effect, 995; on lettuce, seedborne, $\mathrm{S} 7$; on pepper, in California, S7; on peppermint, varietal interaction, S118; on potato, distribution in Pacific Northwest, S57; on potato, lesion nematode and rotation crop effect, S44; on potato, Pratylenchus penetrans synergism, S67; in soil, control by organic amendments and tarping, 253; swine manure effect, factors, S16; on tomato, cropping practice effect, in Ontario, 1011; vegetative compatibility groups, in Israel, 529; on woody ornamentals, vegetative compatibility groups, S29

$-V$. fungicola, on mushroom, population variation, $\mathrm{S} 16$

-V. lecanii, Penicillium digitatum interaction, antibiosis and host defense reactions, 932

Vesonder, R. F., S1, S50, S80

Vianna, M. G. R., S23

Vicia faba, chocolate spot, wyeronic acid synthesis, S55

Vidaver, A. K., 208, S42, S95

Viji, G., S78, S80, S81

Vilchez, M., S120

Vilich, V., S19, S64

Villaréal, L. M. M. A., 1300

Viñas, I., S58
Vinocur, V., S20

Vintal, H., 834

Viola $\times$ wittrockiana, Thielaviopsis basicola on roots, penetration and infection, ultrastructure, 843

Virology

- detection, PCR-based group tests, S49

- vector virus transmission mechanism, disease epidemics, 576

Viruses

-begomoviruses: characterization in Puerto Rico and Caribbean region, S122; detection, techniques in Cuba, S124; new in Brazil, S10

-bipartite, genomic size constraints, cell-to-cell movement, S75

-closterovirus, genetic diversity and evolution, S92; RNA genomic model, S108

-detection, molecular beacon approach, 269

-dsRNA based diagnosis, enhancements, S45

-helper, mathematical models, complexes, 85

-multiple resistance, transgenes and virus segments, S112

-negative-strand RNA, cap-snatching, S111

- potyvirus helper, protease gene, symptoms and protection against other viruses, 467

- RNA mediated defense, S112

- tobamovirus, thermal stability of particles, S52

- transcriptional gene silencing, plant suppressor, S127

—viral suppressor by mobile silencing signal, S127

Visconti, A., S40

Vivar, H. E., 1131

Viveros, M., S10

Vodkin, L. O., S95

Voinnet, O., S112

Von Amsberg, H., S81

von Bodman, S., B., S6

von Broembsen, S. L., S13, S81

Waalwijk, C., 891

Wach, M. J., S47

Wakelyn, P. J., S108

Walcott, R. R., 191

Waldrop, T. A., S21

Walker, F., S22

Walker, H. L., S1, S9

Walkinshaw, C. H., S81, S127, S129

Walsh, K., 448

Wamishe, Y. A., S81

Wang, B., S129

Wang, D., S102

Wang, G.-L., S110

Wang, H. L., S82

Wang, J. (Kentucky), S96

Wang, J-M. (California), S63

Wang, S., S82

Wang, T. B., S82

Wang, X. (Oklahoma), S81

Wang, X. (North Carolina), S82

Wang, Y.-H., S40

Wangsomboondee, T., S65, S82

Ward, J. M. J., S75, S134

Wasilwa, L. A., S82

Wasmann, C. C., 1188

Watanabe, K., 909

Watermelon

-anthracnose, fungicides, application model, S89

-Fusarium wilt, management with resistance biocontrol agents and fumigation, S22 -yellow vine, genotype and ploidy, S18

Watermelon chlorotic stunt virus

- cover photo, June

- sequence comparison, Sudan and Iran, 629

Watson, G., S116

Waugh, M. E. (New Mexico), S109

Waugh, M. M., 243, S82, S119

Wayadande, A. C., 716 
Weaver, C. F., S124

Webb, C., S108

Wedge, D. E., S83, S129

Weeds, P. L., S83

Wegulo, S. N., S27

Wehland, M., S6

Wei, W., 909

Wei, Z.-M., S15, S62, S64, S75

Weiland, G. E., S83

Weisleder, D., S80

Weiss, B., S20

Weissenbach, J., S93

Welliver, R., S46

Wells, M. L., S83

Westphal, A., 401, S83, S120

Westwood, J., S51

Wetteroff, Jr., J. J, S10, S11

Wetzel III, H. C., S97

Wheat

-anti-Fusarium protein gene, S57

-Aspergillus flavus on seeds of, flooding effect, S43

— bacterial seed treatments, in Virginia, S133

-bird-cherry oat aphid, plant response, S57

- diseases, foliar fungicides in Alabama, S11

—dwarf bunt, population variation, 376

-Fusarium graminearum, deoxynivalenol tolerance, $\mathrm{S} 4$

-Fusarium head blight: antagonists, field testing, S69; biocontrol, factors, S42; risk assessment model, S19

-Fusarium spp., deoxynivalenol and nivalenol biosynthesis, S54

—head blight, situation in Iran, 103

-High Plains Disease, ribonucleoprotein complexes, S53

-Karnal bunt: molecular identification of species, S48; species differentiation using PCR, 951; susceptibility, S60

-leaf rust: genetic vulnerability, S81; international collection, molecular polymorphism in virulence, 427; resistance sources, S88; virulence diversity and populations, in Israel, 601

-Magnaporthe grisea, wheat and millet isolate crosses, host specificity, 1060

- powdery mildew: oil for prevention, S69; spore efficacy and host genetics, 1300

-rhizosphere community, methyl ester profiles, S19

—rose grain aphid, predators, interactions with pesticide, $\mathrm{S} 77$

- seedling pathogens in Mississippi, S122

- Septoria tritici blotch: fluquinconazole translocation effect, 1345; interaction using $\beta$-glucuronidase, 297

—speckled snow mold, resistance screening, S119

—stem rust, avirulence genes, DNA markers, gene nomenclature, 819

- stripe rust: durable resistance and trait loci, molecular mapping, S14; plant density and cultivars, 1313

- take-all: manganese effect, S77; prevalence in Pacific Northwest, S63; silthiopham seed treatment, S33

- $\tan$ spot and leaf blotch, infection period models, forecasting system, S19

- $\tan$ spot and Stagonospora blotch, neural network classification, field environment, 108

-yellow head disease, in Kansas, S70

Wheat streak mosaic virus

-nucleotide substitution, accumulation, S33

-RNA viral gene, S25

Wheeler, T. A., S83

White, D. G., 292, 1018, S15, S108

White, G. P., S50

White, J. F., S26
White, K. A., S111

White pine

-blister rust: genetic structure, 1073; past and prognosis, S97

-Lophodermium on needles of, in Canada, S73

White, TJ, S121

Whitfield, A. E., S84

Whiting, E. C., S84

Whittington, D. P., S132

Wichman, R. L., S129

Wicklow, D. T., S50

Widstrom, N. W., S32

Wilcox, W. F., S12, S26, S35, S85

Wilkerson, C., S123

Wilkinson, C., S116

Willemsen-de Klein, M. J. E. I. M., 125

Williams, V., S20, S34

Williams, W. P., S1, S85

Williams-Woodward, J. L., S84, S127

Willmann, M. R., 987

Wilson, A. D., S84

Wilson, C. R., S44, S48, S60, S85

Wilson, D. M., S32, S129

Wilson, J. P., 1169, S84, S129

Wilson, R. G., S34

Winberg, R., S22

Wincker, P., S93

Windels, C. E., S9

Windham, A. S., S84

Windham, G. L., S1, S85

Windom, G. E., 474, S9, S117

Wingfield, B. D., S5, S18, S80

Wingfield, M. J., S5, S16, S18, S67, S80

Winter, M. S., S10

Winter, S., S64

Wintermantel, W. M., S92

Wisler, G. C., S57, S92

Woessner, J., S47

Wolff, D.W., S88

Woloshuk, C. P., S23

Wong, E., S50

Wong, F. P., S85

Wong, J. A. L., S85

Wong, K.-W., 72

Wong, S.-M., 269

Wood, A. K., S85

Wood, C. W., S123

Wood, D. (Washington), S93

Wood, D. L. (California), S8

Wood decay

-fungi for uptake and translocation of minerals, S25

—xylariaceous, mycosymbionts of woodwasps, S84

Wood deterioration, in historic huts, in

Antarctica, S7

Woodford, J. A. T., 1153

Woods, J., S52

Workneh, F., 1375, S85

Worley, C. K., S134

Wright, S., S85

Wu, A.-J., S110

Wu, B. (Canada), S111

Wu, B. M. (California), 827, S85

Wu, K., S110

$\mathrm{Wu}, \mathrm{S}-\mathrm{H}, \mathrm{S} 63$

Wuest, P. J., S6, S38, S131

Wyatt, S. D., S45

Xanthomonas spp., taxonomy, synopsis, letter to editor, 677

$-X$. albilineans, on sugarcane, pathogenicity variability in Guadeloupe, S18

-X. axonopodis: on aroids, genetic diversity, S47; on bell pepper, systemic resistance and major genes, S43; on cassava, genetic diversity in Colombia, 683; on citrus, cultivar interactions, 1383; on citrus, PCR assay for identification, S42; genomes, S108; on pepper, hypersensitivity and temperature, S66; on pepper, strain recovery in field, S65; population dynamics, Colombia, S64

-X. campestris: amended names, letter to editor, 208; detection and extraction methods, S70; genome, S93; harpin, encoding gene, S75; on lettuce: management, S60; systemic infection, $\mathrm{S} 5$; on pepper, races in Oklahoma, S17; population diversity in Nepal, S71; on radish, biocontrol, 327

-X. oryzae, genetic diversity, in Sri Lanka, 415

Xi, K., 94

Xi, P., S39

Xia, J. Q., S49, S103

Xiao, C. L., 995, S46, S86

Xiao, F. M., S86

Xie, W., S1, S50, S80

Xiphinema americanum, nepovirus transmission, retention, $\mathrm{S} 82$

Xiphydria spp., fungal symbionts, antagonism, S84

Xu, H., S86

Xu, X.-M., 568, 738, 1367

Xu, X. Q., S86

$\mathrm{Xu}, \mathrm{Y}$., S60

Xylella fastidiosa

— genome sequence, S93

- genomes, S108

-lytic peptides, S54

- micronutrients and antibiotic effects, S17

-pathotypes, differentiation by protein analysis, S129

- sequence analysis, in plasmids, S31

- strain analysis, 16S rDNA sequence, S13

- strain differentiation, RAPD PCR, S13

- transformation with plasmid DNA, S62

Yam, Y.-K., 491

Yamakawa, R., S78

Yamamoto, H., 762

Yamamoto, M., 595, 762

Yamamoto, T., S76

Yan, Y., S86

Yang, S. S., S14

Yang, X. B., 57, 1375, S34, S85, S86, S99, S100

Yang, Y., S45, S46, S86

Yaniv, Z., 710

Yao, C., S87

Yarnall, M. S., S60

Yasuda, N., S77

Yates, I., S87

Yates, S. R., S102

Yeager, J. T., S69

Yeh, H-H., S91

Yeh, S. D., 228, S14

Yendluri, S., S87

Yin, B., S8

Yoder, O. C., S109

Yoneyama, M., S87

Yonts, C. D., S34

Yoshida, K., 311

Yoshida, S., 285

Yoshikawa, N., 311

Young, C. A., S96

Young, C. H., 1005

Young, T. R., S129

Yourman, L. F., 851, S87

Ypema, H. L., S5, S130, S134

Yu, J., 716, S6, S107

Yu, X.-M., 738, 1367, S68

Yuan, C., S87

Yuen, G. Y., 384, S58

Yuen, J. M. F., S56

Yun, S.-H., S6

Zabala, G., S33

Zadoks, J. C., 1181

Zambino, P. J., 819, S40

Zapata, M., S56, S124 
Zavriev, S., S49

Zazueta, F., S113

Zea mosaic virus, on maize, new in Israel, 505

Zeidan, M., 340

Zeigler, R. S., 621, 1396, S94, S95

Zelenev, V. V., 1181

Zeller, K. A., S40, S46, S68

Zeng, H. C., S87

Zapater, M.-F., 884

Zeringue, H. J., S88

Zeyen, R. J., S35

Zhan, J., 324, 901

Zhang, C., S134

Zhang, G., S111
Zhang, H. S., S11

Zhang, J. X., S24

Zhang, X. (South Dakota), S88

Zhang, X.-S. (United Kingdom), 85

Zhang, Z., 384

Zhang, Y.-P., S38, S88

Zhao, B., S108

Zhao, G., 354

Zhao, J., S100

Zhao, X., 1239

Zhao, Y., S88

Zhao, Z.-Y., S93

Zheng, F. C., S87

Zheng, X. Y., S88, S123
Zhou, J. M., S47, S76, S86

Zhou, X. G., S89

Zhu, P., S24

Zidack, N. K., S101

Zilberstein, A., 297

Zismann, V. L., S29

Zitka, M., S69

Zolobowska, L., S130

Zubiaur, Y. M., S124

Zucchini yellow mosaic virus

- amino acid change, cucurbit symptom affected by, 467

-on cucumber, S78

-heteroduplex mobility assay, 228 